\title{
Atıklardan Siyanürün Geri Kazanımı: SART Prosesi
}

\author{
Recovery of Cyanide from Effluents: SART Process
}

\author{
Elif YILMAZ*a ${ }^{*}$ Ersin Y. YAZICI ${ }^{\mathrm{b}},{\text { Oktay } \text { CELEP }^{\mathrm{c}}, \text { Hacı DEVECI }}^{\mathrm{d}}$ \\ Karadeniz Teknik Üniversitesi, Mühendislik Fakültesi, Maden Mühendisliği Bölümü, 61100, Trabzon
}

• Geliş tarihi / Received: 09.08.2018＜noBreak>•Düzeltilerek geliş tarihi / Received in revised form: 13.12.2018• Kabul tarihi / Accepted: 19.12 .2018

\section{$\ddot{O} z$}

Dünya'da bakır içeriği yüksek altın cevherlerinden altın üretimi giderek artmaktadır. Bakır minerallerinin siyanür çözeltilerinde yüksek oranlarda çözünmesi nedeniyle bu tür cevherlerden altın kazanımında teknik ve ekonomik zorluklar yaşanmaktadır. Bakır içeriği \%0.5’ten yüksek cevherlerden geleneksel siyanür liçi ile altın kazanımı genellikle ekonomik değildir. Yüksek altın kazanımlarına ulaşmak için liç ișleminin yüksek siyanür konsantrasyonlarında $(\mathrm{CN}: \mathrm{Cu}>4)$ yapılması gerekmektedir. Bu durum, hem reaktif maliyetini artırmakta hem de daha fazla siyanür kullanımıyla ilgili olarak çevresel riskin artmasına neden olmaktadır. SART prosesi özellikle bakır içeren altın cevherlerinin yoğun siyanür liçi sonrası atıklardan siyanürün geri kazanımı için geliştirilmiş bir prosestir. Dünya'da ve ülkemizde farklı tesislerde endüstriyel olarak uygulanmaktadır. Prosesin temeli, liç çözeltisinden bakırın asidik koşullarda ( $\mathrm{pH} 4-5)$ sülfür $\left(\mathrm{Na}_{2} \mathrm{~S}\right)$ ilavesiyle $\mathrm{Cu}_{2} \mathrm{~S}$ halinde çöktürülmesi ve böylece siyanürün serbest hale getirilerek geri kazanımına dayanmaktadır. Elde edilen $\mathrm{Cu}_{2} \mathrm{~S}$ yan ürün olarak satılmaktadır. Prosesin performansı sülfür ilavesi, çöktürme süresi, bakır çökeleğinin tikinerde bekleme süresi vd. koşullara bağlıdır. Yüksek saflıkta bir $\mathrm{Cu}_{2} \mathrm{~S}$ çökeleği elde etmek için sülfür ilavesinin hassas bir şekilde kontrol edilmesi gerekmektedir. Bu çalışmada, SART prosesinin kimyasal esasları ve performansını etkileyen parametreler detaylı olarak irdelenmiştir. Prosesin ilk yatırım ve işletme maliyetleri 1şığında genel bir ekonomik analizi de sunulmuştur.

Anahtar kelimeler:Bakır İçeren Altın Cevherleri, Siyanür Liçi, Siyanür Geri Kazanımı, SART Prosesi

\begin{abstract}
Gold production from copper-rich gold ores is increasing at worldwide. Owing to the high dissolution of copper minerals in cyanide solutions, technical and economic difficulties have been faced in treatment of those ores. Gold extraction from ores that contain $>0.5 \% \mathrm{Cu}$ is often uneconomic by traditional cyanide leaching. High cyanide concentrations ( $\mathrm{CN}: \mathrm{Cu}>4)$ should be maintained to achieve high gold extractions. This, in turn, leads to an increase in reagent consumptions and environmental risk due to higher use cyanide. SART process was developed in particular for recovery of cyanide from the effluents of intensive cyanidation of Au-Cu ores. The process is applied worldwide and in Turkey at industrial scale. It is based on precipitation of copper in the form of $\mathrm{Cu}_{2} \mathrm{~S}$ from leach solutions under acidic conditions ( $\mathrm{pH}$ 4-5) by addition of sulphide (as $\mathrm{Na}_{2} \mathrm{~S}$ ) leading to the release of free cyanide prior to its recovery. $\mathrm{Cu} \mathrm{u}_{2} \mathrm{~S}$ is sold as a by-product. The performance of the process is dependent on the addition of sulphur, precipitation period, retention of copper precipitates in the thickener and other parameters. Addition of sulphur should be strictly controlled to obtain a high purity $\mathrm{Cu}_{2} S$ precipitate. In this study, chemical principles and factors affecting the performance of SART process are discussed in detail. A general economic analysis of the process in view of capital and operating costs is also presented.
\end{abstract}

Keywords: Copper-gold Ores, Cyanide Leaching, Cyanide Recovery, SART Process

\footnotetext{
*a Elif YILMAZ; elifkoc@ktu.edu.tr; Tel: (0462) 37736 40; orcid.org/0000-0001-8789-0007

${ }^{\mathrm{b}}$ orcid.org/0000-0002-8711-0784 $\quad{ }^{\mathrm{c}}$ orcid.org/0000-0001-9024-4196 $\quad{ }^{\mathrm{d}}$ orcid.org/0000-0003-4105-0912
} 


\section{Giriş}

Siyanür liçi, seçimli bir yöntem değildir. Altın ve gümüşün yanı sıra altın cevherlerinde bulunan bazı mineraller de çözünerek siyanür ve oksijen sarfiyatını artırmaktadır (Fleming, 1992; La Brooy vd., 1994; Marsden ve House, 2006). Özellikle son yıllarda, Dünya'da ve ülkemizde, bakır içeriği yüksek cevherlerden altın kazanımı artmaktadır. Bakır minerallerinin siyanür çözeltilerindeki yüksek çözünürlüğ̈ reaktif tüketimini artırmakta ve başta altın kazanımına olumsuz etkisi olmak üzere birçok teknik sorunlara neden olmaktadır (Sceresini ve Breuer, 2016). Yüksek siyanür tüketimi nedeniyle bu tür cevherler için uygun siyanür geri kazanım yöntemlerinin kullanılması teknik ve ekonomik açıdan bir zorunluluktur (Fleming, 2011). Siyanürün geri kazanımı amaciyla geliştirilen aktif karbon adsorpsiyonu, iyon değişimi (IX), solvent ekstraksiyon (SX), elektro-kazanım (EW) ve AVR gibi yöntemler/prosesler bulunmaktadır (Dai vd., 2012; Xie vd., 2013; Y1lmaz vd., 2018). Bununla beraber, yüksek konsantrasyonda bakır içeren çözeltilerden siyanürün geri kazanımında karşılaşılan teknik zorluklar nedeniyle endüstriyel ölçekte uygulanan yöntemler sınırlıdır. SART prosesi (Sulphidisation, Acidification, Recycling and Thickening), bakır içeriği yüksek siyanür çözeltilerinden siyanürün geri kazanımını ve bakırın da yan ürün olarak elde edilmesini sağlayan endüstriyel bir proses olarak Dünya'da ve ülkemizdeki bazı tesislerde uygulanmaktadır (Botz vd., 2011; Adams, 2013; Estay, 2018).

$\mathrm{Bu}$ çalışmada, bakır minerallerin siyanür çözeltilerindeki davranışı ve bakır varlığının liç prosesinde oluşturduğu teknik sorunlar irdelenmiştir. SART prosesinin tarihi gelişimi ve temelleri detaylı olarak tartışılmışıtır. Endüstriyel ölçekli SART tesislerinin özellikleri ve teknik performansları sunulmuştur. Ayrıca, prosesin ilk yatırım ve işletme maliyetlerini etkileyen parametreler irdelenmiştir.

\section{Bakır Minerallerinin Siyanür Çözeltilerinde Davranışı ve Altın Kazanımına Etkileri}

Özellikle oksitli/karbonatlı ve ikincil sülfürlü bakır mineralleri siyanür çözeltilerinde yüksek oranlarda çözünmektedirler (Tablo 2) (Sceresini ve Breuer, 2016). Bazı bakır minerallerinin siyanür ortamında çözünmesi (1)-(5) no'lu tepkimeler ile gösterilebilir (Parga, 2011; Sceresini ve Breuer, 2016). Görüldügüü gibi, $1 \mathrm{~mol}$ bakır mineralinin çözünmesi için 3-8 $\mathrm{mol} \mathrm{CN}^{-}$ tüketilmektedir (1)-(5). Düşük siyanür konsantrasyonlarında bakır, $\mathrm{CuCN}\left(\mathrm{K}_{\mathrm{sp}}=3 \times 10^{-20}\right)$ halinde çökmektedir. Ortamda yeterli seviyede siyanür bulunduğunda ise $\mathrm{Cu}(\mathrm{CN})_{\mathrm{n}}{ }^{1-\mathrm{n}}(2 \leq \mathrm{n} \leq 4)$ şeklinde kompleksler oluşturarak çözünmektedir (1)-(5) (Dai vd., 2012). Bakır-siyanür çözeltilerinde $\left(\mathrm{Cu}-\mathrm{CN}-\mathrm{H}_{2} \mathrm{O}\right)$ bakır bileşiklerinin kararlı olduğu koşullar Şekil 1'deki Pourbaix (EhpH) diyagramında görülmektedir (Dai vd., 2012).

$\mathrm{Cu}_{2} \mathrm{O}+6 \mathrm{CN}^{-}+\mathrm{H}_{2} \mathrm{O} \rightarrow 2 \mathrm{Cu}(\mathrm{CN})_{3}^{-2}+2 \mathrm{OH}^{-}$

$2 \mathrm{CuO}+7 \mathrm{CN}^{-}+\mathrm{H}_{2} \mathrm{O} \rightarrow 2 \mathrm{Cu}(\mathrm{CN})_{3}^{-2}+2 \mathrm{OH}^{-}+\mathrm{CNO}^{-}$

$$
\begin{gathered}
\mathrm{Cu}_{2} \mathrm{~S}+7 \mathrm{CN}^{-}+1 / 2 \mathrm{O}_{2}+\mathrm{H}_{2} \mathrm{O} \rightarrow \\
2 \mathrm{Cu}(\mathrm{CN})_{3}{ }^{-2}+2 \mathrm{OH}^{-}+\mathrm{CNS}^{-}(3) \\
2 \mathrm{CuS}^{2} 8 \mathrm{CN}^{-}+1 / 2 \mathrm{O}_{2}+\mathrm{H}_{2} \mathrm{O} \rightarrow \\
2 \mathrm{Cu}(\mathrm{CN})_{3}{ }^{-2}+2 \mathrm{OH}^{-}+2 \mathrm{CNS}^{-}(4) \\
2 \mathrm{CuCO}_{3}+7 \mathrm{CN}^{-}+2 \mathrm{OH}^{-} \rightarrow \\
2 \mathrm{Cu}(\mathrm{CN})_{3}^{-2}+\mathrm{CNO}^{-}+\mathrm{H}_{2} \mathrm{O}
\end{gathered}
$$

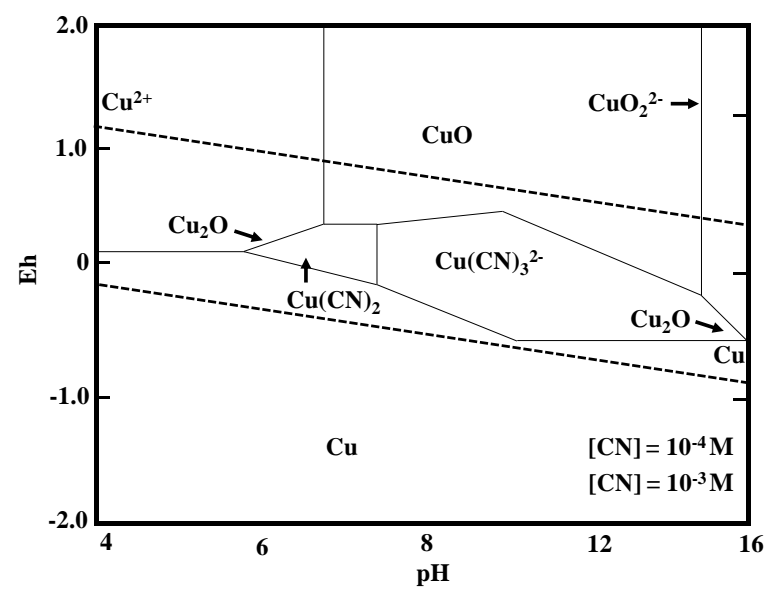

Şekil 1.Cu-CN- $\mathrm{H}_{2} \mathrm{O}$ sistemi için Eh-pH diyagramı (Sceresini ve Breuer, 2016)

Liç aşamasında bakırın çözünürlüğü, bakır minerallerinin türü ve siyanür konsantrasyonuna bağlı olduğu kadar cevherin tane boyutu, bakır tenörü, uygulanan liç yöntemi ve liç süresi gibi birçok parametreye bağlıdır. Örneğin, Tablo 1'de görüldüğü gibi, yığın liçi uygulanan farklı altın cevherlerinden çözünen bakır oranı (14-39\%) cevherin özellikleri ve tane boyutuna göre değişmektedir (Estay, 2018).

Siyanür liçinde tipik reaktif tüketimleri cevherin mineralojik yapısı ve bileşimine bağlı olarak 0.25$2 \mathrm{~kg} \mathrm{NaCN} /$ ton cevher arasında değişmektedir (Marsden ve House, 2006). Ancak, bakır içeriği yüksek cevherlerde siyanür tüketimi cevherdeki her $\% 1 \mathrm{Cu}$ için yaklaşık $30 \mathrm{~kg} /$ ton $\mathrm{NaCN}$ 'dir 
(Muir, 2011). Eğer, cevherde sülfürlü bakır mineralleri de bulunuyor ise tüketim $51.5 \mathrm{~kg} /$ ton'a kadar ulaşabilir (Sceresini, 2005). Buna göre, \%1 $\mathrm{Cu}$ içeren bir altın cevherinin siyanür tüketimi normal koşullarla kıyaslandığında 26-206 kat (51.5 kg/ton'a karş1 0.25-2 kg/ton) daha yüksektir. $\mathrm{Bu}$ nedenle, cevherlerden siyanür liçi ile altın kazanımının ekonomik olabilmesi için cevherin bakır içeriğinin $\% 0.5$ 'den düşük olmas1 gerekmektedir (Muir vd., 1991; Dai vd., 2012). Bas vd. (2015) yaptıkları bir araştırmada, \%1.1 Cu içeren bir altın cevherinin (Mastra/Gümüşhane) tipik koşullarda yapılan siyanür liçinde $(1.5 \mathrm{~g} / \mathrm{L}$ $\mathrm{NaCN}, 24$ sa.), nispeten yüksek siyanür tüketimine $(18 \mathrm{~kg} /$ ton) rağmen çok düşük $(\% 6.7)$ altın kazanımı elde etmişlerdir (Şekil 2). Aynı liç süresinde bakırın önemli oranda $(>\% 24 \mathrm{Cu})$ çözündüğünü belirlemişlerdir. Aynı araştırmacılar, yüksek altın kazanımlarına (>\%97) ulaşabilmek için yüksek siyanür konsantrasyonlarında $(>5 \mathrm{~g} / \mathrm{L} \quad \mathrm{NaCN})$ çalışılması gerektiğini bildirmişlerdir.

Tablo 1. Yı̆̆ın liçinde $\mathrm{Au}$ ve $\mathrm{Cu}$ kazanımları (Estay, 2018)

\begin{tabular}{lccccc}
\hline \multicolumn{2}{l}{ Parametre } & Proje 1 & Proje 2 & Proje 3 & Proje 4 \\
\hline $\begin{array}{l}\text { Tane } \\
(\mathrm{mm})\end{array}$ & Boyutu & $\% 80-$ & $\% 80-$ & $\% 100-9.53$ & $\% 80-$ \\
$\mathrm{Au}$ & Tenörü & 25.40 & 19.05 & & 12.70 \\
$(\mathrm{~g} / \mathrm{t})$ & 0.4 & 0.67 & 1.51 & 0.61 \\
$\mathrm{Cu}$ Tenörü (\%) & 0.05 & 0.07 & 0.07 & 0.04 \\
$\mathrm{Au}$ Verimi (\%) & 65 & $55-70$ & 65 & 81 \\
$\mathrm{Cu}$ Verimi (\%) & 20 & 14 & 39 & 30 \\
\multicolumn{2}{l}{ Atıkta Cu (\%) } & 0.040 & 0.058 & 0.042 & 0.028 \\
\hline
\end{tabular}

Tablo 2. Siyanür çözeltilerinde bakır minerallerinin çözünürlükleri (Tane boyutu: $-150 \mu \mathrm{m}$; Cevherdeki bakır minerali içeriği: \%0.183-0.267; Başlangıç $\mathrm{NaCN}$ kons.: \%0.10; Sıvı/katı oranı: 10/1; Süre: 24 saat) (Sceresini ve Breuer, 2016)

\begin{tabular}{|c|c|c|c|c|c|}
\hline \multirow{2}{*}{ Mineraller } & \multirow{2}{*}{ Formülleri } & \multicolumn{2}{|c|}{24 saatte $^{a}$ çözünen toplam Cu (\%) } & \multicolumn{2}{|c|}{6 saatte $^{\mathrm{b}}$ oda sıcaklığında çözünme } \\
\hline & & $23^{\circ} \mathrm{C}$ & $45^{\circ} \mathrm{C}$ & g NaCN/g Cu & $\% \mathrm{Cu}$ \\
\hline Azurit & $2 \mathrm{CuCO}_{3} \cdot \mathrm{Cu}(\mathrm{OH})_{2}$ & 94.5 & 100 & 3.62 & 91.8 \\
\hline Malakit & $2 \mathrm{CuCO}_{3}(\mathrm{OH})_{2}$ & 90.2 & 100 & 4.48 & 99.7 \\
\hline Kalkozin & $\mathrm{Cu}_{2} \mathrm{~S}$ & 90.2 & 100 & 2.76 & 92.6 \\
\hline Kovellin & $\mathrm{CuS}$ & - & - & 5.15 & 95.6 \\
\hline Bakır & $\mathrm{Cu}$ & 90.0 & 100 & - & - \\
\hline Kuprit & $\mathrm{Cu}_{2} \mathrm{O}$ & 85.5 & 100 & 4.94 & 96.6 \\
\hline Bornit & $\mathrm{FeS} .2 \mathrm{Cu}_{2} \mathrm{~S} . \mathrm{CuS}$ & 70.0 & 100 & 5.13 & 96.0 \\
\hline Enarjit & $\mathrm{Cu}_{3} \mathrm{AsS}_{4}$ & 65.8 & 75.1 & - & - \\
\hline Tetrahedrit & $(\mathrm{Cu}, \mathrm{Fe}, \mathrm{Ag}, \mathrm{Zn})_{12} \mathrm{Sb}_{4} \mathrm{~S}_{13}$ & 21.9 & 43.7 & - & - \\
\hline Krikozol & $\mathrm{CuSiO}_{3} \cdot \mathrm{nH}_{2} \mathrm{O}$ & 11.8 & 15.7 & - & - \\
\hline Kalkopirit & $\mathrm{CuFeS}_{2}$ & 5.6 & 8.2 & 2.79 & 5.8 \\
\hline
\end{tabular}

${ }^{\mathrm{a}}$ Hedley ve Tabachnick (1958)

${ }^{\mathrm{b}}$ Lower ve Booth (1965) (Siyanür tüketimleri, birim bakır için harcanan NaCN miktarı olarak verilmiştir)

Çözeltideki bakır, sadece liç aşamasında değil altının çözeltiden kazanımı aşamasında da teknik zorluklara neden olmaktadır. Yüklü liç çözeltisinden altının kazanımı sırasında bakır da aktif karbonlara adsorplandığından dolayı altının adsorpsiyonunu olumsuz yönde etkilemektedir. Bakırın aktif karbona adsorpsiyonu, çözelti koşullarına bağlı olarak bakır-siyanür türlerinin dağılımı ve bu türlerin aktif karbonlara adsorpsiyon eğilimi ile yakından ilişkilidir. Bakırsiyanür komplekslerinin aktif karbona adsorpsiyon eğilim sırası $\mathrm{Cu}(\mathrm{CN})_{2}>\mathrm{Cu}(\mathrm{CN})_{3}{ }^{-2}>$ $\mathrm{Cu}(\mathrm{CN})_{4}{ }^{-3}$ şeklindedir (Adams vd., 2008; Fleming, 2011).

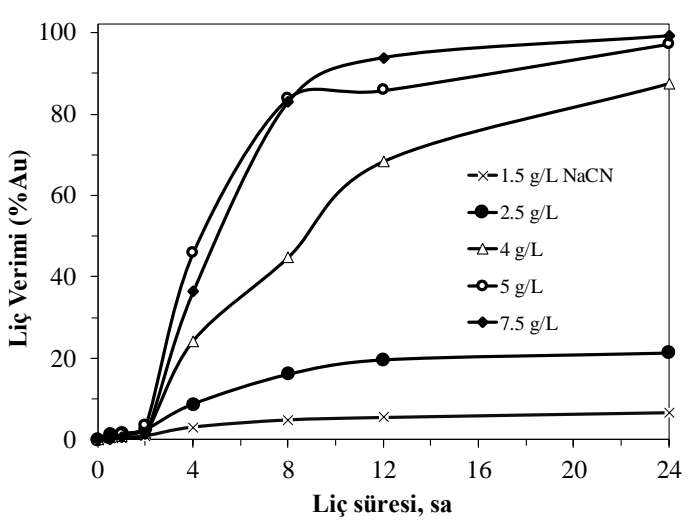

Şekil 2. Bakır içeren $(\% 1.1 \mathrm{Cu})$ altın cevherinden altın kazanımına siyanür konsantrasyonunun etkisi (Bas vd., 2015) 
Siyanür konsantrasyonu ve $\mathrm{pH}$ arttıkça $\mathrm{Cu}(\mathrm{CN})_{3}{ }^{-2}$ ve $\mathrm{Cu}(\mathrm{CN})_{4}^{-3}$ türleri daha baskın hale geleceği için (Şekil 1), seçimli bir altın kazanımı için adsorpsiyon işleminin yüksek siyanür konsantrasyonu $(\mathrm{CN}: \mathrm{Cu}>4)$ ve $\mathrm{pH}$ koşullarında gerçekleştirilmesi gerekmektedir (Fleming 2011; Dai vd., 2012). Ancak, adsorpsiyon işleminin yüksek siyanür konsantrasyonunda gerçekleştirilse dahi karbona adsorbe olan bakır miktarı altına eşit ve hatta daha yüksek olduğu bildirilmiştir (van Deventer vd., 2014).

Yüklü liç çözeltilerinden altın kazanımında çinko sementasyonu (Merrill-Crowe prosesi) uygulandığ 1 durumda, $\mathrm{Cu}(\mathrm{CN})_{2}{ }^{-}$kompleksi altın ile birlikte çökme eğiliminde olduğu için hem çinko tüketimini artırmakta hem de altının saflığını azaltmaktadır (Adams vd., 2008; González vd., 2013). Altının elektro-kazanım aşamasında, çözeltide (tipik olarak 200-1000 $\mathrm{mg} / \mathrm{L} \mathrm{Au}$ ) bakır konsantrasyonu yüksek ise, altından daha elektronegatif olmasına rağmen altın ile birlikte katotta toplanabilmektedir. Bakır dışında civa, kurşun ve gümüş gibi metaller altından önce katotta indirgenerek akım verimini ve katot saflığını olumsuz etkileyebilmektedir (Habashi, 1999; Dai vd., 2012).Katotun bakır vd. metaller ile kirlenmesine bağlı olarak külçe altın saflığı da azalmaktadır (Fleming, 2010). Bakır içeren cevherlerinden altın kazanımında karşılaşılan teknik zorluklar nedeniyle bu tür cevherler için farklı prosesler önerilmektedir. Bakırı ilk aşamada uzaklaştırmak için flotasyon (Bulatovic, 1997; Forrest vd., 2001), asit/alkali çözeltiler ile liç (Bas vd., 2012a; Yazici vd., 2015) veya Sceresini prosesi uygulanabilir. Farklı araştırmacılar, siyanür liçi öncesi ön havalandırma (Kondos vd., 1995; Bas vd., 2012a; Deschênes vd., 2012) veya kurşun nitrat ilavesinin (Deschênes ve Prud'homme, 1997; Deschênes vd., 2012) etkilerini de test etmişlerdir. Bakırlı cevherlerde daha etkin altın kazanımları sağlayan tiyosülfat, amonyaklı siyanür gibi alternatif liç sistemleri de uygulanabilir (Muir ve Aylmore, 2005; Bas vd., 2011, 2015; Sceresini ve Breuer, 2016; Ahlatc1, 2016). Son yıllarda yaygınlaşan endüstriyel bir yöntem de, yüksek siyanür konsantrasyonlarında $(\mathrm{CN}: \mathrm{Cu}>4)$ liç işlemi gerçekleştirildikten sonra çözeltiden siyanürün (ve yan ürün olarak bakırın) SART prosesi ile geri kazanılmasıdır (Dai vd., 2012; Fleming ve Melashvili, 2016). Siyanürün geri kazanımı reaktif kullanımının azaltılması, atık barajlarının daha düşük kapasitede yapılmasını ve atık çözeltinin daha az toksik bileşen içermesine bağlı olarak potansiyel çevresel riskleri azaltmasını sağlaması nedeniyle önemli teknik ve ekonomik avantajlar sunmaktadir (Fleming, 2016).

\section{SART Prosesi}

Bakır içeriği yüksek siyanür çözeltilerinden siyanürün ve bakırın geri kazanılması için geliştirilmiştir (Fleming, 2010; Estay vd., 2012; Cuenca vd., 2012). SART prosesi, yığın liçinden elde edilen yüklü liç çözeltilerine (kolon içinde karbon (CIC) öncesi) veya tank/yığın liçini takiben adsorpsiyon sonras1 (CIL/CIP/CIC) devresi sonundaki boş çözeltilere uygulanabilmektedir (Ford vd., 2008; Baker vd., 2017). Yığın liçi sonrası katı sıvı ayırımına gerek duyulmadığı için çözelti doğrudan SART tesisine beslenebilir. SART prosesi adsorpsiyon öncesi uygulandığında çözeltideki bakırın karbona adsorbe olmasının önüne geçilmekte ve böylece yüklü karbondan altının sıyırılması öncesinde bakırın sıyırılmasına ihtiyaç kalmamaktadır (SGS, 2008).

\subsection{Tarihsel Gelișimi}

SART prosesinin geçmişten günümüze kadar gelişimi Tablo 3'te özetlenmiştir. SART prosesi, 1990'1 y yllarda SGS Lakefield Research (Kanada) tarafından geliştirilmiş ve pilot çapta yapılan testlerden (Lobo-Marte projesi) elde edilen ilk araştırma sonuçları MacPhail vd. (1998) tarafından yayımlanmıştır (Fleming ve Melashvili, 2016). Proses, endüstriyel ölçekte ilk kez Telfer altın madeninde (Avustralya) uygulanmıştır (Ford vd., 2008). Daha sonraki yıllarda (2006-2013) farklı ülkelerde SART tesisleri faaliyete geçmiştir (Tablo 3). SART prosesi nispeten yeni bir teknoloji olmasına bağlı olarak endüstriyel ölçekli SART tesisi sayısı henüz 10'un altındadır (Baker vd., 2017; Estay, 2018).

\subsection{SART Prosesinin Kimyasal Esaslart}

Proses esas olarak sülfürleştirme (sulphidisation), asitleştirme (acidification), geri kazanım (recycling) ve koyulaştırma (thickening) aşamalarından oluşmaktadır. Prosesin temel adımlarını gösteren bir akım şeması Şekil 3'te sunulmuştur. Sülfürleştirme aşamasında siyanür çözeltisine $\mathrm{Na}_{2} \mathrm{~S}$ veya genellikle NaHS ilave edilmektedir. Hidrojen sülfür $\left(\mathrm{H}_{2} \mathrm{~S}\right)$ gazı da sülfür kaynağı olarak kullanılabilir. Hidrojen sülfürün $\left(\mathrm{H}_{2} \mathrm{~S}\right)$, biyolojik süreçler ile elementel sülfürden veya sülfattan indirgenerek üretilmesi de mümkündür (Lawrence ve Lopez, 2011). 
Tablo 3. SART prosesinin tarihsel gelişimi (Estay, 2018)

\begin{tabular}{|c|c|}
\hline Yll & Prosesin Gelişimi \\
\hline 1986 & Potter vd. (1986) SART Prosesinin temelini oluşturan MNR Prosesini patentini almıştır. \\
\hline 1998 & $\begin{array}{l}\text { MacPhail vd. (1998) Lobo-Marte projesinin pilot tesisi hakkında SART Prosesi ile ilgili ilk araştırma sonuçlarını } \\
\text { yayınlamışlardır. }\end{array}$ \\
\hline 2001 & Barter vd. (2001) Telfer SART Prosesinin pilot tesisi ve yapılan test çalışmaları ile ilgili ilk makaleyi yayınlamışlardır. \\
\hline 2006 & İlk endüstriyel SART tesisi (60 m³/sa kapasite) (Telfer/Avustralya) devreye alınmıştır. \\
\hline 2008 & Luvia de Oro SART Tesisi Meksika'da devreye alınmıştır. Tesiste biyo-sülfür kullanılmıştır. \\
\hline 2008 & 1400 m³/sa kapasiteli Yanacocha SART Tesisi Peru'da devreye alınmıştır. \\
\hline 2009 & $140 \mathrm{~m}^{3}$ /sa kapasiteli Gedabek (Azerbaycan) SART Tesisi devreye alınmıştır. \\
\hline 2010 & Türkiye'de 120 m³/sa kapasiteli Mastra SART Tesisi faaliyete başlamıştır. \\
\hline 2012 & Maricunga 'da (Şili) 750 m³/sa kapasiteli en büyük ikinci SART Tesisi devreye alınmıştır. \\
\hline 2013 & Türkiye'deki ikinci SART Tesisi olan Çöpler SART Tesisi $\left(380 \mathrm{~m}^{3} / \mathrm{sa}\right)$ devreye alınmıştır. \\
\hline
\end{tabular}

Sülfür ilavesinin ardından çözelti, $\mathrm{H}_{2} \mathrm{SO}_{4}$ ilavesiyle asitleştirilerek $\mathrm{pH}$ 4-5' te bakırın $\mathrm{Cu}_{2} \mathrm{~S}$ (sentetik kalkozin) formunda $(\log K=34.60)$ (Zhang vd., 1997) çökmesi (6) sağlanmaktadır. $\mathrm{Cu}-\mathrm{S}-\mathrm{CN}-\mathrm{H}_{2} \mathrm{O}$ sisteminde bakır bileşiklerinin kararlı olduğu Eh-pH bölgeleri Şekil 4'de görülmektedir. Şekil 5'te Cu-S-CN sistemi için bakır bileşiklerinin $\mathrm{pH}$ 'ya göre dağ 11 ımı ve asidik

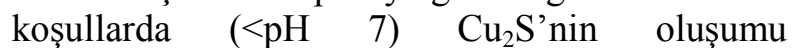
görülmektedir. Asitleştirme aşamasında oluşan $\mathrm{HCN}$ ve $\mathrm{H}_{2} \mathrm{~S}$ gazlarından kaynaklanabilecek çevresel sorunları engellemek amaciyla asitleștirme ișlemi sızdırmaz kapalı tanklarda yapılmaktadır ve oluşan gazlar nötralize edilmek üzere gaz yıkama sistemine (pH 10-11) aktarılmaktadır (Ford vd., 2008).

$$
\begin{array}{r}
2 \mathrm{Cu}(\mathrm{CN})_{3}{ }^{-2}+3 \mathrm{H}_{2} \mathrm{SO}_{4}+\mathrm{S}^{-2} \rightarrow \\
\mathrm{Cu}_{2} \mathrm{~S}_{(\mathrm{k})}+6 \mathrm{HCN}_{(\mathrm{s})}+3 \mathrm{SO}_{4}^{-2}
\end{array}
$$

Asitleştirme işlemi sonrası $\mathrm{Cu}_{2} \mathrm{~S}$ çökelekleri kat1/siv1 ayırımı (tikinerleme + filtrasyon) yapılarak asidik çözeltiden ayrılır. SART prosesinde, doğrudan filtrasyon yerine önce tikinerlerde koyulaştırma işlemi ile çökelek katı oranı \%10-15'e artırılarak filtrasyon için gerekli pulp hacmi önemli ölçüde azaltılır (Sceresini ve Breuer, 2016). Bu filtrasyon tesisi, yüksek ilk yatırım giderlerinin azaltılması bakımından önemlidir.

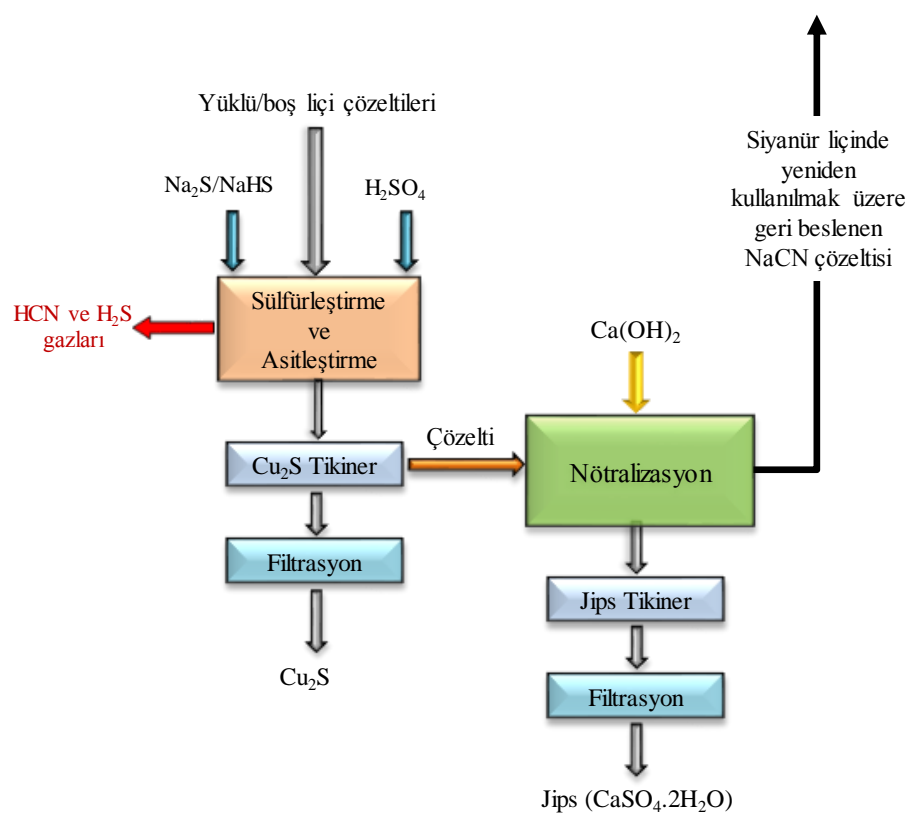

Şekil 3. SART prosesinin genel akım şeması (Nodwell vd., 2012'den değiştirilerek) 
Katı/sıvı ayırımı sonrasında kireç ilavesi ile çözelti pH'sı 10.5-11'e yükseltilir. Kireç tüketimi (tipik $0.5-0.9 \mathrm{~kg} \mathrm{Ca}(\mathrm{OH})_{2} / \mathrm{m}^{3}$ ) çözeltideki sülfat ve karbonat iyonlarına bağlı olarak değişmektedir (Estay, 2018). Bu sırada oluşan HCN alkali çözelti içinde absorbe edilerek $\mathrm{Ca}(\mathrm{CN})_{2}$ formunda siyanür geri kazanılmaktadır (7) (Şekil 3) (Fleming, 2011; Estay vd., 2012; Xie vd., 2013).

$2 \mathrm{HCN}_{(\mathrm{s})}+\mathrm{Ca}(\mathrm{OH})_{2} \rightarrow \mathrm{Ca}(\mathrm{CN})_{2}+2 \mathrm{H}_{2} \mathrm{O}$

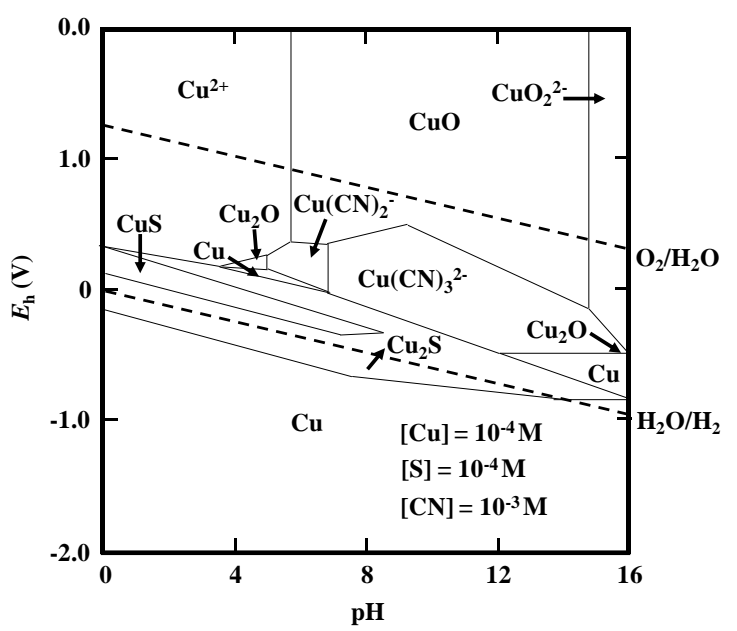

Şekil 4. Cu-S-CN-H $\mathrm{H}_{2} \mathrm{O}$ sisteminde bakır için EhpH diyagramı (Marsden ve House, 2006)

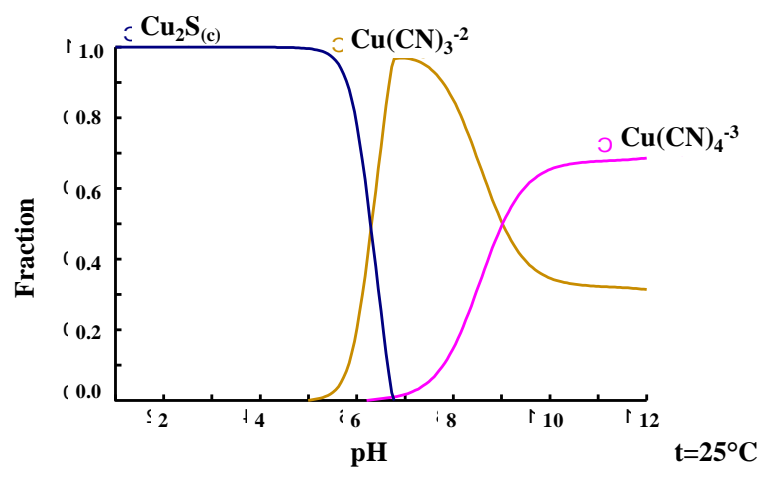

Şekil 5. Cu-S-CN sisteminde pH'ya bağlı olarak bakır türlerinin değişimi $(\mathrm{Cu}=16 \mathrm{mM}(1 \mathrm{~g} / \mathrm{L}) ; \mathrm{CN}$ : $79 \mathrm{mM}(3.9 \mathrm{~g} / \mathrm{L}) ; \mathrm{CN}: \mathrm{Cu}$ (molar) $=5 ;\left[\mathrm{HS}^{-}\right]=32$ $\mathrm{mM} ; 25^{\circ} \mathrm{C}$ ) (Medusa, 2009)

SART prosesini etkileyen temel parametreler NaHS konsantrasyonu ( $\mathrm{S}: \mathrm{Cu}$ oranı), $\mathrm{pH}$, siyanür konsantrasyonu $(\mathrm{CN}: \mathrm{Cu}$ oran1) ve süredir. Etkin bir çöktürme işlemi için sülfür ilavesinin uygun miktarda yapılması gerekmektedir. Çözeltide bulunan bakır dışındaki diğer metallerin de konsantrasyonuna bağlı olarak genelde NaHS ilavesi stokiyometrik ihtiyacın üzerinde (\%110120) seçilmektedir (Ford vd., 2008). Örneğin, Telfer SART tesisinde sülfür dozajı stokiyometrik oranın \%116-138'i ( $\mathrm{pH} 4.5$ ), Yanacocha (Peru) tesisinde \%120-140'1 (pH 4.0-4.5), Gedabek
(Azerbaycan) tesisinde \%120'si (pH 5.5) ve Mastra (Türkiye) tesisinde \%115'i (pH 4.0-5.0) olarak ilave edilmektedir (Estay, 2018). Aşırı sülfür ilavesi sülfür tüketimini artırmaktadır (Estay vd., 2013). Ayrıca, aşırı sülfür ilavesi nedeniyle çöktürme aşamasında bakır ile beraber çinko ve gümüş gibi metaller de sülfür bileşikleri $\left(\mathrm{Ag}_{2} \mathrm{~S}\right.$ veya $\left.\mathrm{ZnS}\right)$ halinde çökerek $\mathrm{Cu}_{2} \mathrm{~S}$ çökeleğinin saflığını azaltmakta, gümüş kaybına neden olmaktadır (8) ve (9) (Marsden ve House, 2006; Xie vd., 2013; Estay, 2018). Dreisinger vd. (2008) SART prosesinde yüklü siyanür liçi çözeltisinden bakır ile beraber molibdenin $\mathrm{Mo}_{2} \mathrm{~S}$ olarak çökmesine bağlı olarak çökelekte $\approx \% 1$ oranında molibden tespit etmiştir. Benzer şekilde, arsenik de sülfür bileşiği halinde $\left(\mathrm{As}_{2} \mathrm{~S}_{3}\right)$ bakır ile beraber çökmektedir (Lopez vd., 2014).

$2 \mathrm{Ag}(\mathrm{CN})^{-2}+\mathrm{S}^{-2}+4 \mathrm{H}^{+} \rightarrow \mathrm{Ag}_{2} \mathrm{~S}+4 \mathrm{HCN}$

$\mathrm{Zn}(\mathrm{CN})_{4}^{-2}+\mathrm{S}^{2-}+4 \mathrm{H}^{+} \rightarrow \mathrm{ZnS}+4 \mathrm{HCN}$

Çinko, alkali siyanür çözeltilerinde de $\mathrm{ZnS}$ olarak çöktürülebilir. Bundan dolayı, çinko içeriği yüksek siyanür çözeltilerinden çinkonun uzaklaştırılması için Velardena prosesi geliştirilmiştir (Marsden ve House, 2006). Yeni yapılan bir çalışmada (Koc vd., 2016), $\mathrm{Na}_{2} \mathrm{~S}$ ilave edilen alkali siyanür çözeltilerinden $(\mathrm{pH} 11.5)$ çinko/gümüşün altından seçimli olarak ( $\geq 96 \%)$ çöktürülebildiği ve aynı koşullarda bakırın sınırlı $(\leq \% 11)$ olarak çöktüğü bildirilmiştir.

Çöktürme sırasında meydana gelen yan tepkimeler, reaktif (sülfür, siyanür) sarfiyatının artmasına ve $\mathrm{Cu}_{2} \mathrm{~S}$ çökeleğinin saflığının azalmasina neden olmaktadır. Teorik olarak saf $\mathrm{Cu}_{2} \mathrm{~S}$ çökeleği \%79.9 $\mathrm{Cu}$ içermesine karşın SART prosesinde elde edilen çökeleğin bakır içeriği ortalama \%65'dir (Estay vd., 2013). Bakırın $\mathrm{Cu}_{2} \mathrm{~S}$ formunda çöktürülmesi istenir; ancak, proses koşullarına (çözelti kimyası, sülfür dozajı, $\mathrm{pH}$ vd.) bağlı olarak CuS (kovellin) ( $\log K=22.20$;Zhang vd.,(1997) de oluşabilir (10) (Estay vd., 2013).

$$
\begin{array}{r}
2 \mathrm{Cu}(\mathrm{CN})_{3}^{-2}+3 \mathrm{H}_{2} \mathrm{SO}_{4}+\mathrm{S}^{-2} \rightarrow \\
\mathrm{CuS}_{(\mathrm{k})}+6 \mathrm{HCN}_{(\mathrm{s})}+3 \mathrm{SO}_{4}^{-2}
\end{array}
$$

Aşırı sülfür ilavesine (ve diğer çöktürme koşullarına) bağlı olarak yüklü liç çözeltisinden altın kayıpları olabilmektedir (Botz vd., 2015; Fleming ve Melashvili 2016). Dreisinger vd. (2008), bir $\mathrm{Cu}-\mathrm{Au}$ cevherinin yüklü liç çözeltisinden SART prosesiyle elde ettikleri bakır çökeleğinde 3-13 g/t Au tespit etmişlerdir. Başka bir çalışmada (Botz vd., 2011), çöktürme aşamasında altının bir kısmının, muhtemelen 
çökeleğe adsorbe olarak katı kısımda kaybedildiği bildirilmiştir. Araştırmacılar, çözeltideki altın konsantrasyonunda bir düşüş gözlemlemiş ve çökeleğin altın içeriğini 7-36 g/t $\mathrm{Au}$ olarak belirlemişlerdir.Botz vd. (2015), bir SART tesisinde (Yanacocha/Peru) çöktürme aşamasında altın ve gümüş kaybının sırasıyla $\% 1.6$ ve $\% 98.7$ olduğunu belirtmiştir. Ford vd. (2008) tarafindan Şili'deki (Maricunga) bir SART tesisine yönelik yapılan testlerde, yüklü çözeltideki altının az bir k1smının $(<\% 0.5)$ bakır sülfür çökeleğinde kaybedildiği belirtilmiştir. Çökeleğin Au içeriği 3$7 \mathrm{~g} / \mathrm{t}$ olarak belirlenmiştir. Aynı araştırmacılar (Ford vd., 2008), jips çökeleğinde de çok düşük seviyede $(0.1 \mathrm{~g} / \mathrm{t})$ altın tespit etmişlerdir. Bazı araştırmacıların bulgularının aksine, Meksika'daki bir yığın liçi tesisinde, adsorpsiyon aşaması öncesi SART uygulanmış ve altın kaybının çok düşük olduğu $\left(\mathrm{Cu}_{2} \mathrm{~S}\right.$ kekinin gözenek suyunda $\left.<\% 0.1\right)$ bildirilmiştir (Baker vd., 2017). Bununla beraber, ergitme tesislerine gönderilen bakır sülfür çökeleğindeki altın için ilave ödeme yapılmaktadır.

Çöktürme aşamasında karşılaşılan altın kayıpları ve üretilen bakır çökeleğinin düşük saflığı vd. teknik sorunlar nedeniyle, çöktürmeye etki eden sülfür dozaj1, siyanür konsantrasyonu, $\mathrm{pH}$ vd. parametreler hassas bir şekilde kontrol edilmelidir. Simons ve Breuer (2013a), SART prosesinde $\mathrm{S}: \mathrm{Cu}$ oran1 $(0.4-0.6), \mathrm{CN}: \mathrm{Cu}$ oran1 (35) ve pH'nın (4-5.5) siyanür geri kazanımına (ve bakırın çökmesine) etkilerini araştırmışlar ve uygun koşullarda yüksek (>\%95) siyanür ve bakır kazanımına ulaşmışlardır. Araştırmacılar, test ettikleri koşullarda (pH 4-5.5) pH'nın önemli bir etkisi olmadığını bulmuşlardır. Aynı çalışmada, $\mathrm{S}: \mathrm{Cu}$ oranının prosesi etkileyen en önemli parametre olduğu belirlenmiştir. $\mathrm{S}: \mathrm{Cu}$ oranının stokiyometrik orandan $(\mathrm{S}: \mathrm{Cu}=0.50)$ yüksek $(\mathrm{S}: \mathrm{Cu}=0.55-0.60) \quad$ seçilmesi gerektiğini belirtmişlerdir. Bunun nedenini, asitleştirme sırasında sülfürün bir kısmının tiyosülfat ve tiyosiyanata oksitlenerek tüketilmesine bağlamışlardır. Araştırmacılar, ayrıca, $\mathrm{Cu}_{2} \mathrm{~S}$ yüzeylerinin katalitik etkisiyle de sülfürün oksitlenebileceğini ileri sürmüşlerdir. Sülfürün dışında, $\mathrm{Cu}_{2} \mathrm{~S}$ de oksijen varlığında oksitlenerek bakır-siyanür ve tiyosiyanat $\left(\mathrm{SCN}^{-}\right)$gibi bileşiklere dönüşerek (11)-(12) sülfür tüketimini artırabilmektedir (Simons ve Breuer, 2013a). Bakırın $\mathrm{CuCN}$ halinde çökmesi de bakır çökeleğinin saflığını ve niteliğini olumsuz yönde etkilediği için istenmeyen bir durumdur.

$$
\begin{array}{r}
\mathrm{Cu}_{2} \mathrm{~S}+5 \mathrm{HCN}_{(\mathrm{a})}+1 / 2 \mathrm{O}_{2} \rightarrow \\
2 \mathrm{Cu}(\mathrm{CN})_{2}+\mathrm{SCN}^{-}+3 \mathrm{H}^{+}+\mathrm{H}_{2} \mathrm{O} \quad(11)
\end{array}
$$

$$
\begin{array}{r}
\mathrm{Cu}_{2} \mathrm{~S}+3 \mathrm{HCN}_{(\mathrm{a})}+1 / 2 \mathrm{O}_{2} \rightarrow \\
2 \mathrm{CuCN}+\mathrm{SCN}^{-}+\mathrm{H}^{+}+\mathrm{H}_{2} \mathrm{O}
\end{array}
$$

Sicaklığın $\left(4-20^{\circ} \mathrm{C}\right)$ SART prosesini önemli ölçüde etkilemediği bildirilmiştir (Ford vd., 2008). Çöktürme süresi de SART performansını belirleyen önemli parametrelerden biridir. Sülfür ilavesi sonrasında bakır kısa sürelerde (10-15 dk.) çökmektedir (Ford vd., 2008; Simons ve Breuer, 2013a,b). Ancak, çok uzun sürelerde, çöken bakır çözünmeye başlayabilmektedir (CuS formuna geçmektedir) (Simons ve Breuer, 2013a ve b). Simons ve Breuer (2013a), bakırın çok kısa sürede $(<10 \mathrm{dk}$.) çökmesini takiben çözeltideki konsantrasyonunun artmaya başladığını (yani çözündüğünü) tespit etmiştir. $\mathrm{Bu}$ artışı, uzun çöktürme sürelerinde $\mathrm{Cu}_{2} \mathrm{~S}$ 'nin çözünmesi ve/veya oksitlenerek $\mathrm{CuS}$ haline dönüşmesine bağlamışlardır.

$\mathrm{Cu}_{2} \mathrm{~S}$ 'nin bakır siyanür kompleksi halinde çözünmesi (13) no'lu tepkimede gösterilmiştir. Yüksek asidik koşullarda $(<\mathrm{pH} \quad 4) \quad \mathrm{CuCN}$ oluşmaktadır (14) (Şekil 5). Bu tepkimeler (13) ve (14) sonucunda $\mathrm{H}_{2} \mathrm{~S}$ gazı açığa çıkmaktadır (Simons ve Breuer, 2013a). Bakırın çözünmesi, $\mathrm{Cu}_{2} \mathrm{~S}$ ürün miktarının azalmasına ve geri kazanılan çözeltideki bakırın artışına bağlı olarak tesis performansını olumsuz etkilemektedir.

$$
\begin{aligned}
& 2 \mathrm{Cu}(\mathrm{CN})_{2}+\mathrm{H}_{2} \mathrm{~S}_{(\mathrm{g})}+2 \mathrm{H}^{+} \\
& \mathrm{Cu}_{2} \mathrm{~S}+2 \mathrm{HCN}_{(\mathrm{a})}
\end{aligned} \rightarrow
$$

$\mathrm{Cu}_{2} \mathrm{~S}$ 'nin sülfür iyonları ve oksijen varllğğnda CuS'ye dönüşmesi (bakırın $\mathrm{Cu}(\mathrm{I})$ 'den $\mathrm{Cu}(\mathrm{II})$ 'ye oksitlenmesi) (15)-(17) no'lu tepkimeler ile gösterilebilir (Simons ve Breuer, 2013a; Fleming ve Melashvili, 2016). Sülfür, asidik $(<\mathrm{pH} 6)$ çözeltilerde $\mathrm{H}_{2} \mathrm{~S}$ halinde bulunduğu için SART prosesi koşullarında (pH 3-5) (17) no'lu tepkime baskın olacaktır (Fleming ve Melashvili, 2016).

$$
\begin{aligned}
& \mathrm{Cu}_{2} \mathrm{~S}+\mathrm{NaHS}+1 / 2 \mathrm{O}_{2} \rightarrow \\
& 2 \mathrm{CuS}+\mathrm{NaOH}\left(\Delta G^{0}\right. \\
& \mathrm{Cu}_{2} \mathrm{~S}+\mathrm{Na}_{2} \mathrm{~S}+1 / 2 \mathrm{O}_{2}+\mathrm{H}_{2} \mathrm{O} \rightarrow \\
& 2 \mathrm{CuS}+2 \mathrm{NaOH}\left(\Delta G_{\left(25^{\circ} \mathrm{C}\right)}^{0}=-165 \mathrm{~kJ}\right) \\
& \mathrm{Cu}_{2} \mathrm{~S}+\mathrm{H}_{2} \mathrm{~S}_{(\mathrm{a})}+1 / 2 \mathrm{O}_{2} \overrightarrow{\mathrm{kJ}}^{0} \\
& 2 \mathrm{CuS}+\mathrm{H}_{2} \mathrm{O}\left(\Delta G_{\left(25^{\circ} \mathrm{C}\right)}^{0}=-244 \mathrm{~kJ}\right)
\end{aligned}
$$

Sülfürün bir kısmı da hidrojen sülfürün $\left(\mathrm{H}_{2} \mathrm{~S}\right)$ doğrudan oksijen ile tepkimesi sonucunda elementel sülfür (18), tiyosülfat ve politiyonatlara dönüşerek $\mathrm{Cu}_{2} \mathrm{~S}$ ile beraber katıda toplanabilmektedir (Fleming ve Melashvili, 2016). $\mathrm{Bu}$ durum, katıdaki $\mathrm{S}: \mathrm{Cu}$ oranının yükselmesine 
ve dolayısıyla bakır içeriğinin düşmesine neden olabilmektedir.

$$
\begin{aligned}
\mathrm{H}_{2} \mathrm{~S}+1 / 2 \mathrm{O}_{2} \rightarrow \mathrm{S}^{0}+\mathrm{H}_{2} \mathrm{O} \\
\left(\Delta G_{\left(25^{\circ} \mathrm{C}\right)}^{0}=-217 k J\right)
\end{aligned}
$$

Fleming ve Melashvili (2016), yukarıdaki tepkimenin (17) $\mathrm{Cu}_{2} \mathrm{~S}$ 'nin $\mathrm{CuS}$ 'e dönüşme tepkimelerine (15)-(17) göre termodinamik olarak daha istemli olduğunu belirterek bakır çökeleğindeki $\mathrm{S}: \mathrm{Cu}$ oranı artışının buna (15)-(17) bağlanabileceğini ifade etmişlerdir. $\mathrm{S}: \mathrm{Cu}$ oranları açısından, $\mathrm{Cu}_{2} \mathrm{~S}+\mathrm{S}^{0}$ den oluşan bir $\mathrm{Cu}_{2} \mathrm{~S}$ çökeleğinin $\mathrm{CuS}$ 'den $(\mathrm{S}: \mathrm{Cu} \approx 1)$ kimyasal olarak farklı olduğunu belirlemek zordur. Ayrıca, $\mathrm{Cu}_{2} \mathrm{~S}$ 'nin $\mathrm{CuS}$ 'e dönüşmesi sırasındabakırın $\mathrm{Cu}(\mathrm{I})$ 'den $\mathrm{Cu}(\mathrm{II})$ 'ye oksitlendiği genel bir kabul olmasina rağmen,Goh vd. (2006) tarafindan yapılan bir karakterizasyon çalışmasında kovellin mineralindeki $(\mathrm{CuS})$ bakırın, kabul edilenin aksine $\mathrm{Cu}$ (II) formunda değil $\mathrm{Cu}$ (I) formunda olduğu ileri sürülmüştür. Araştırmacılar, CuS'nin aslında $\mathrm{Cu}_{2} \mathrm{~S}_{2}$ halinde $\left(\mathrm{Cu}(\mathrm{I})\right.$ ve 2 sülfür atomu (biri $\mathrm{S}^{2-}$ diğeri $\left.\mathrm{S}^{0}\right)$ ) olduğunu ifade etmişlerdir. Fleming ve Melashvili (2016), bakır çökeleğindeki S:Cu oranı artışının $\mathrm{H}_{2} \mathrm{~S}, \mathrm{HS}^{-}$ve $\mathrm{S}_{2}{ }^{-}$türlerinin metal sülfürlere $\left(\mathrm{Cu}_{2} \mathrm{~S}\right.$ gibi) yüksek adsorpsiyon eğilimi ile de ilişkilendirilebileceğini belirtmişlerdir.

Çökeleğin $\mathrm{S}: \mathrm{Cu}$ oranının teorik olarak olması gereken 1:2 $\left(\mathrm{Cu}_{2} \mathrm{~S}\right.$ için) orandan yüksek olması ve 1:1'e yaklaşması yukarıda tartışılan birçok farklı neden(ler)e $\left(\mathrm{Cu}_{2} \mathrm{~S}^{\prime}\right.$ in $\mathrm{CuS}$ 'ye dönüşümü, $\mathrm{S}^{2-{ }^{-}}$nin $\mathrm{S}^{0}$ 'a dönüşümü, $\mathrm{Cu}_{2} \mathrm{~S}$ yüzeyine sülfür adsorpsiyonu) bağlanabilir. Bununla beraber, bu reaksiyonlar yavaştır ve aşırı sülfür $(\mathrm{S}: \mathrm{Cu}>0: 5-1)$ ve oksijen varlığında gerçekleşmektedir. Çökelekteki yüksek $\mathrm{S}: \mathrm{Cu}$ probleminin, sülfür ilavesinin hassas kontrol edilmediği, yarı-sürekli çalışan ve dolayısıyla çökeleğin oksijene uzun süre maruz kaldığı SART tesislerinde yaşandığı bildirilmiştir (Fleming ve Melashvili, 2016).

Aşırı sülfür ilavesinin neden olduğu başka bir teknik sorun da, bakır çökeleklerinin ince boyutlu olması ve buna bağlı olarak tikinerde daha zor çökelmesidir (Fleming ve Melashvili, 2016). Çökelmenin zorlaşması, metal sülfür bileşiklerine $\left(\mathrm{Cu}_{2} \mathrm{~S}\right.$ gibi) çözeltideki serbest sülfür türlerinin $\left(\mathrm{HS}^{-}\right.$ve $\mathrm{S}_{2}^{-}$) adsorbe olarak tane yüzeyini negatif hale getirmesi ve bunun sonucunda da tanelerin birbirini itmesine bağlanabilir (Mokone vd., 2010; Fleming ve Melashvili, 2016). Düşük pH koşulları $\left(\mathrm{H}^{+}\right.$iyonlarının artması) negatif yüzey yükünü dengeleyerek çökme hızının artmasını sağlamaktadır. Fleming ve Melashvili (2016)stokiyometrik $\mathrm{S}: \mathrm{Cu}$ oranında (0.5) ve
$\mathrm{S}: \mathrm{Cu}=1$ 'de çöktürme testleri yaparak bakır çökeleklerinin/topaklarının tane boyutlarını incelemiştir. Stokiyometrik orandaki testte elde edilen ürünün tane boyutunun, $\mathrm{S}: \mathrm{Cu} \approx 1$ oranında elde edilen ürünün boyutuna göre çok daha iri (bazıları $>1 \mathrm{~mm}$ ) olduğunu tespit etmişlerdir. Araştırmacılar, aşırı sülfür ilavesinin oluşturduğu teknik sorunlar nedeniyle $\mathrm{S}: \mathrm{Cu}$ oranının stokiyometrik oranı $(0.50)$ aşmaması gerektiğini ileri sürmüştür.

SART tesislerinde, $\mathrm{Cu}_{2} \mathrm{~S}$ kristal oluşumunu/büyümesini ve dolayısıyla tikinerleme işlemini hızlandırmak amacıyla çökelek içeren çözeltinin bir kısmı reaktöre geri beslenmekte yani aşılama yapılmaktadır. Genel kabulün aksine, Fleming ve Melashvili (2016) SART prosesinde uygulanan aşılama işleminin çökeleklerin büyümesine olumlu bir katkısının olmadığını deneysel olarak ortaya koymuştur.

Tikinerleme aşamasında, tanelerin topaklanması ve böylece çökme süresinin hızlandırılması, berrak bir üst akım temini, katı oranı yüksek ve kolay filtre edilebilir bir alt akım elde edilmesi amaciyla flokülant ilave edilmektedir. Flokülant ilavesinin önemli bir avantaj1, alt akımdaki katı yoğunluğunun artmasina ve filtrasyon özelliklerinin (filtrasyon hızı ve filtre keki nem oranı) iyileşmesine bağlı olarak daha küçük bir filtrasyon ünitesini yeterli kılmasıdır. $\mathrm{Bu}$ da yatırım maliyetini olumlu etkileyen bir faktördür. Flokülant kullanılmaması 2 önemli dezavantaj içermektedir (Fleming ve Melashvili, 2016):

i) Çökme hızının yavaşlamasına bağlı olarak daha yüksek bir tikiner gerekli olacağı için yatırım maliyeti artar,

ii) Üst akıma kaçan ince boyutlu $\mathrm{Cu}_{2} \mathrm{~S}$ taneleri alkali siyanür çözeltisinde çözünür; ancak, bu da proseste (liç+SART) asit, baz ve sülfür tüketimini artırır.

Flokülant kullanımının bilinen avantajlarına rağmen, SGS tarafindan yapılan bir pilot tesis çalışmasında, flokülant kullanılmadığı durumda daha yüksek katı oranında (\%40-50'ye karş1 \%1015) ve daha kolay filtre edilebilen bir alt akım elde edilmiştir (Fleming ve Melashvili, 2016). Ayrıca, ilginç bir şekilde, Fleming ve Melashvili (2016)'nin yaptığı bir çalışmada, flokülant ilavesinin çökeleklerin tane boyutuna önemli bir etkisi olmadığı bulunmuştur. Fleming ve Melashvili (2016), flokülant ilave edildiğinde endüstriyel SART tesislerinde filtrasyon 
aşamasında önemli teknik zorluklar yaşandığı için flokülant kullanılmamasını önermektedirler.

Fleming ve Melashvili (2016), SART prosesinde iyi kalitede ve kolay $\mathrm{K} / \mathrm{S}$ ayırımı yapılabilen bir $\mathrm{Cu}_{2} \mathrm{~S}$ çökeleği elde edebilmek için aşağıdaki koşulların sağlanması gerektiğini ifade etmiştir:

$>$ Çözeltinin bakır içeriği çok yüksek olsa bile aşırı sülfür ilavesinden kaçınılmalı ( $\mathrm{S}: \mathrm{Cu}$ oranı 0.50'yi aşmamalı),

$>$ Çökme süresi $\mathrm{pH}$ 3-5' ta mümkün olduğunca kisa tutulmali,

$>$ Sülfür ilavesi düşük dozajlar şeklinde yapılmal1
$>$ Oksijen ile teması mümkün olduğunca engellenmeli,

> Koyulaştırma aşamasında flokülant kullanılmamal,

> SART prosesi kesikli veya yar1-kesikli değil, sürekli çalıştırılmalıdır.

SART tesislerinde dikkat edilmesi gereken önemli bir konu da bakır sülfür çökeleklerinin yanma eğilimidir. Bazı SART tesislerinde depolama alanlarındaki bakır sülfürlerin kendiliğinden yanmaya başladıkları bildirilmiştir (Estay vd., 2013). Bu nedenle, bakır sülfür çökeleklerinin depolandığ 1 alanlar yanma riskini azaltacak şekilde seçilmelidir. Tablo 4'de SART prosesinin avantaj ve dezavantajları sunulmuştur.

Tablo 4. SART Prosesinin avantaj ve dezavantajları(Mudder ve Botz, 2001; Fleming, 2003; Breuer vd., 2005; Ritcey, 2005; Deveci vd., 2006; Marsden ve House, 2006; SGS, 2009; Botz vd., 2011; Fleming, 2011; Dai vd., 2012; SGS, 2013; Xie vd., 2013 ; Estay vd., 2013; Simons ve Breuer, 2013a; Sceresini ve Breuer, 2016; Baker vd., 2017)

\begin{tabular}{|c|c|}
\hline Avantajlar & Dezavantajlar \\
\hline $\begin{array}{ll}\checkmark & \text { Siyanür bozundurma maliyetleri } \\
& \text { önemli ölçüde azalmakta } \\
\checkmark & \text { Bakır içeren çözeltiler için uygun } \\
\checkmark & \text { Bakır Cu } \mathrm{Cu}_{2} \mathrm{~S} \text { halinde yan ürün olarak } \\
& \text { kazanılmakta } \\
\checkmark & \text { Daha yüksek saflıkta altın külçesi } \\
& \text { eldesi edilmekte } \\
\checkmark & \text { Aktif karbona adsorbe olan bakır } \\
\text { miktarının azalması (eğer adsorpsiyon } \\
\text { öncesi uygulanıyorsa) }\end{array}$ & $\begin{array}{ll}- & \text { Nispeten yeni bir teknoloji, endüstriyel ve kesiksiz çalışan tesis sayısı sınırlı } \\
- & \text { Maliyet, işletilebilirlik ve metalürjik performansı hakkında bilgi/tecrübe } \\
\text { eksikliği var } & \\
- & \text { Isşletme maliyeti yüksek } \\
- & \text { Kontrolü zor } \\
- & \text { Çöktürme aşamasında altın/gümüş kayıpları mümkün (çökelekte } \leq 36 \mathrm{~g} / \mathrm{t} \mathrm{Au} \text { ) } \\
- & \text { Berrak çözeltilere uygulanabilir }(\mathrm{K} / \mathrm{S} \text { ayırımı gerekli) } \\
- & \text { AVR prosesinde olduğu gibi, geri kazanılan siyanürü daha konsantre hale } \\
& \text { getirmemektedir } \\
- & \text { Çinko vd. metaller de çökerek } \mathrm{Na}_{2} \mathrm{~S} / \mathrm{NaHS} \text { tüketimini artırır } \\
- & \mathrm{Na}_{2} \mathrm{~S} / \mathrm{NaHS} \text { ilavesi hassas kontrol gerektirir } \\
- & \text { Zararlı HCN ve } \mathrm{H}_{2} \mathrm{~S} \text { gazları oluşumu } \\
- & \text { Yüksek asit }(>\mathrm{pH} 10.5 \text { 'dan } \mathrm{pH} 4-5 \text { 'e) ve baz tüketimi (nötralizasyon aşaması) } \\
- & \text { Asitleştirme kapalı-sıdırrmaz tanklarda gerçekleştirilmeli } \\
- & \text { Bakır sülfürün kendiliğinden yanması söz konusu olabilir }\end{array}$ \\
\hline
\end{tabular}

\subsection{Endüstriyel Uygulamalar}

Dünya'daki bazı endüstriyel SART tesisleri Tablo 5 'de sunulmuştur. SART prosesinin uygulanmasına yönelik bazı proje çalışmaları Casino (Kanada), Caspiche (Şili), Lobo-Marte (Şili) ve Luiri (Zambiya) tesislerinde devam etmektedir (Estay, 2018). SART tesislerinde (Tablo 5) tipik siyanür geri kazanım verimleri $>\% 65$ ve bakır kazanım verimleri >\%80'tir (Cuenca vd., 2012; Adams, 2013). Mevcut SART tesislerinin bir kısmı maden sahasına uzak ve küçük tesislerdir. Büyük çoğunluğu ise sürekli (continuous) çalışmamaktadır. Bu nedenlere bağlı olarak, SART prosesinin gerçek maliyeti, işletilebilirliği ve metalürjik performansı hakkında bilgi ve tecrübe eksikliği bulunmaktadır (Baker vd., 2017).
SART prosesinin endüstriyel olarak ilk kez uygulandığ 1 yer olan Telfer madeninde, 1998 ve 2001 yılları arasında tesiste işlenen cevherin bakır tenörünün $128 \mathrm{~g} /$ ton'dan $1418 \mathrm{~g} /$ ton'a yükselmesi ile birlikte tesiste bazı teknik zorluklar ile karşılaşılmıştır. Kabul edilebilir altın kazanımlarına ulaşmak için liç işleminde (CIL) siyanür konsantrasyonunun yükseltilmesi, atık barajına gönderilen siyanür seviyesinin ve dolayısıyla hem siyanür bozundurma hem de yeni siyanür alımı maliyetinin artmasına neden olmuştur. Teknik zorlukları aşmak ve özellikle yükselen maliyetleri azaltmak amaciyla farklı seçenekler değerlendirilmiş ve SART prosesinin uygulanmasına karar verilmiştir (Barter vd., 2001). 
Yığın liçi uygulanan Peru'daki Yanacocha SART tesisine ait akım şeması Şekil 8'de sunulmuştur. Yüklü liç çözeltisi $(5-35 \mathrm{mg} / \mathrm{L} \mathrm{Ag})$ doğrudan SART prosesine gönderilmektedir (Tablo 5) (Estay, 2018). SART tesisinden çıkan bakırı uzaklaştırılmış yüklü liç çözeltisi, altın kazanımı için aktif karbon kolonlarına (CIC) gönderilmektedir. Yığın liçi uygulanan Maricunga (Şili) tesisinin akım şeması Şekil 7'de gösterilmiştir (Adams, 2013). SART tesisinde geri kazanılan siyanür çözeltisi yeniden yığın liçine beslenmektedir (Şekil 7). Benzer bir yığın liçi tesisi Lluvia de Oro'da (Meksika) bulunmaktadır. $\mathrm{Bu}$ tesise 2008 yılında, ADR devresi çıkışı boş çözeltinin beslendiği bir SART tesisi entegre edilmiştir (Baker vd., 2017).

Bakırın yanı sıra çinko içeriği yüksek cevherler için de SART/Velardena prosesinin uygulanmasına yönelik çalışmalar bulunmaktadır. Kanada'lı bir firma tarafından çinko içeriği yüksek bir gümüş cevherine $(73.4 \mathrm{~g} / \mathrm{t} \mathrm{Ag}$, \%2.79

Zn) (Sierra Mojada Projesi, Coahuila/Meksika) yönelik bir proje yürütülmektedir (Barry, 2013a,b,c ve 2018). Metalurjik testlerde, cevherdeki çinko minerallerinin siyanürde çözünürlüğünün yüksek olduğu belirlenmiştir. Kurulması planlanan tesisin [kırma/öğütme][VAT liçi]-[Merril Crowe prosesi]-[SART prosesi]-[Pb flotasyonu] süreçlerini içermesi, yüksek çinko içerikli (\%63-64) bir çinko sülfür çökeleğinin elde edilmesi öngörülmüştür (Şekil 6) (Barry, 2013a). Ön metalurjik testlerde \%75-80 gümüş kazanımına ulaşılmıştır. SART prosesine yönelik ön testlerde yüksek (>\%98) siyanür geri kazanımına ve \%40-50 çinko kazanımına ulaşılmıştır (Barry, 2013a,c).

Ülkemizde bakır içeriği yüksek cevherlerden altın üretimi artmaktadır (Y1lmaz vd., 2018). Bu tür cevherlerden altın kazanımı sırasında teknik ve ekonomik zorluklarla karşılaşılmaktadır (Corrans ve Kyle, 2000; Fleming, 2011). Bu nedenle, bakırın olumsuz etkilerini kontrol etmek amaciyla bazı tesislere SART prosesi kurulmuştur (Botz vd., 2011; Nodwell vd., 2012). Mastra altın madenine ait akım şeması Şekil 9'da sunulmuştur.

Tablo 5. Dünya'daki SART tesisleri ve teknik detayları (YLÇ: Yüklü liç çözeltisi) (Cuenca vd., 2012 ve Estay, 2018'den derlenerek)

\begin{tabular}{|c|c|c|c|c|c|c|c|}
\hline Tesis & $\begin{array}{c}\text { Telfer } \\
\text { (Avustralya) }\end{array}$ & $\begin{array}{c}\text { Yanacocha } \\
\text { (Peru) }\end{array}$ & $\begin{array}{c}\text { Lluvia de Oro } \\
\text { (Meksika) }\end{array}$ & $\begin{array}{c}\text { Gedabek } \\
\text { (Azerbaycan) }\end{array}$ & $\begin{array}{c}\text { Mastra } \\
\text { (Türkiye) }\end{array}$ & $\begin{array}{l}\text { Maricunga } \\
\text { (Şili) }\end{array}$ & $\begin{array}{c}\text { Çöpler } \\
\text { (Türkiye) }\end{array}$ \\
\hline Başlangıç & 2006 & 2008 & 2008 & 2009 & 2010 & 2012 & 2013 \\
\hline Liç türü & $\begin{array}{c}\text { Tank liçi+ } \\
\text { CIL }\end{array}$ & Yığın liçi ${ }^{b}$ & Yığın liçi & Yığın liçi & $\begin{array}{c}\text { Tank liçi+ } \\
\text { CIP/CIC }\end{array}$ & Yığın liçi & Yığın liçi \\
\hline $\begin{array}{l}\text { SART besleme } \\
\text { kaynağı }\end{array}$ & YLÇ & YLÇ & Boş çözelti & YLÇ & Boş çözelti & YLÇ & Boş çözelti \\
\hline Kapasite $\left(\mathrm{m}^{3} / \mathrm{h}\right)$ & 60 & 1400 & 340 & 140 & 120 & 750 & 380 \\
\hline $\begin{array}{l}\text { WAD CN } \\
(\mathrm{mg} / \mathrm{L})\end{array}$ & - & - & 350 & - & 800 & - & - \\
\hline $\mathrm{Cu}(\mathrm{mg} / \mathrm{L})$ & 1000 & 1000 & 150 & 800 & 1500 & 450 & 400 \\
\hline $\begin{array}{l}\text { CN geri kazanımı } \\
(\%)\end{array}$ & - & 65 & 95 & - & 80 & 94 & - \\
\hline $\begin{array}{l}\text { Cu Kazanımı } \\
(\%)\end{array}$ & 90 & $70-99$ & 90 & $90-95$ & 90 & 90 & 94 \\
\hline Hedef $\mathrm{Cu}(\mathrm{mg} / \mathrm{L})^{\mathrm{a}}$ & $<70$ & $<<20$ & 15 & - & 15 & - & 24 \\
\hline $\begin{array}{l}\text { Cu üretimi } \\
\text { (ton/gün) }\end{array}$ & 0.9 & 20 & 1 & 2.5 & 4 & 9.0 & 3.4 \\
\hline $\begin{array}{l}\text { Çökeleğin Cu } \\
\text { Tenörü (\%) }\end{array}$ & 70 & $6-50$ & 65 & $55-60$ & $55-65$ & 70 & $68-74$ \\
\hline Kaynak & $\begin{array}{l}\text { (Estay; 2008; Estay vd., 2012; } \\
\text { Simons ve Breuer, 2013b) }\end{array}$ & $\begin{array}{l}\text { (Cuenca vd., 2012; Estay, } \\
\text { 2018) }\end{array}$ & $\begin{array}{l}\text { (Lawrence ve Lopez, } \\
\text { 2011; Estay vd., 2012) }\end{array}$ & (Estay vd., 2012) & $\begin{array}{c}\text { (Lawrence ve Lopez, } \\
\text { 2011; Estay vd., 2012; } \\
\text { BQE Water, 2017a) } \\
\end{array}$ & $\begin{array}{c}\text { (Estay vd., 2012; BQE- } \\
\text { Water, 2017b) } \\
\end{array}$ & $\begin{array}{c}\text { (Alacer Gold, 2013, } \\
\text { 2014) } \\
\end{array}$ \\
\hline
\end{tabular}

Şekil 6.Sierra Mojada Ag-Zn cevheri (Coahuila/Meksika) için önerilen akım şeması (Barry, 2013a'den değiştirilerek)

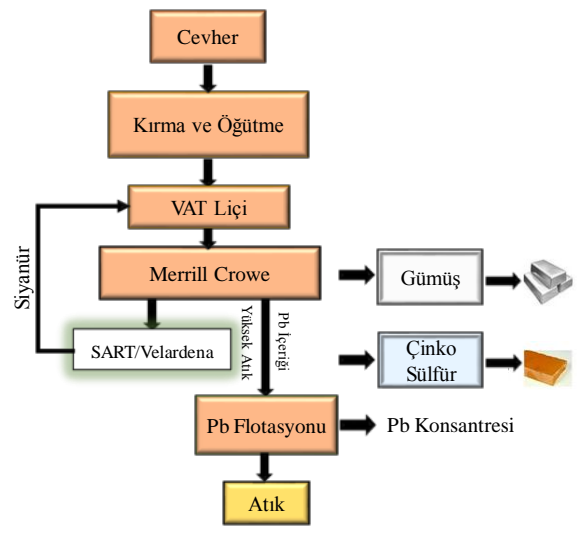




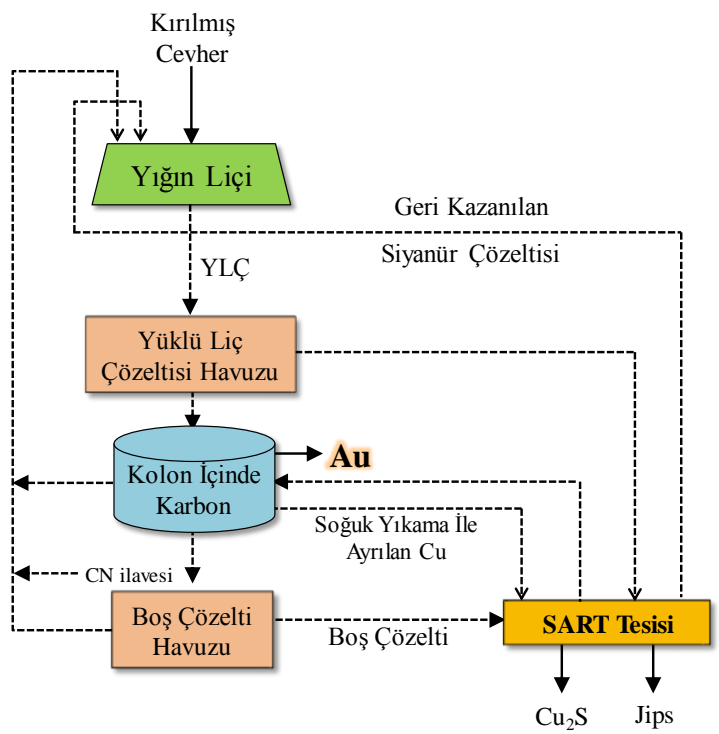

Şekil 7.Maricunga tesisi (Şili) SART prosesi akım şeması (Adams, 2013)

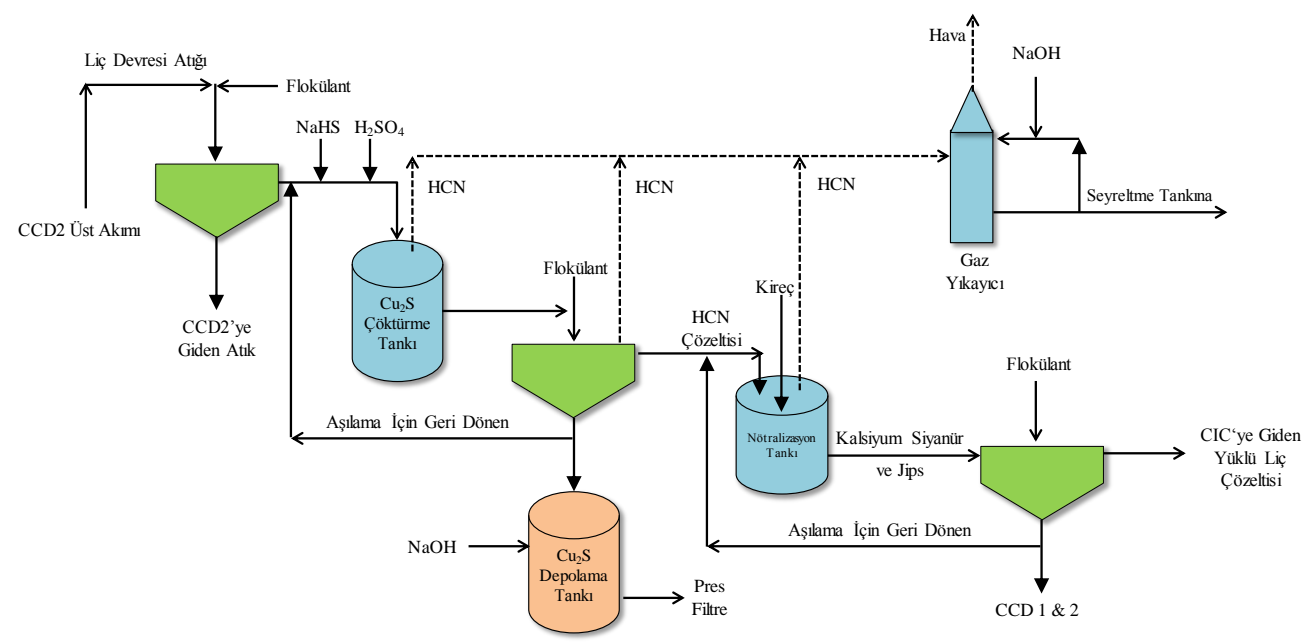

Şekil 8.Yanacocha tesisi (Peru) SART prosesi akım şeması (Adams, 2013)

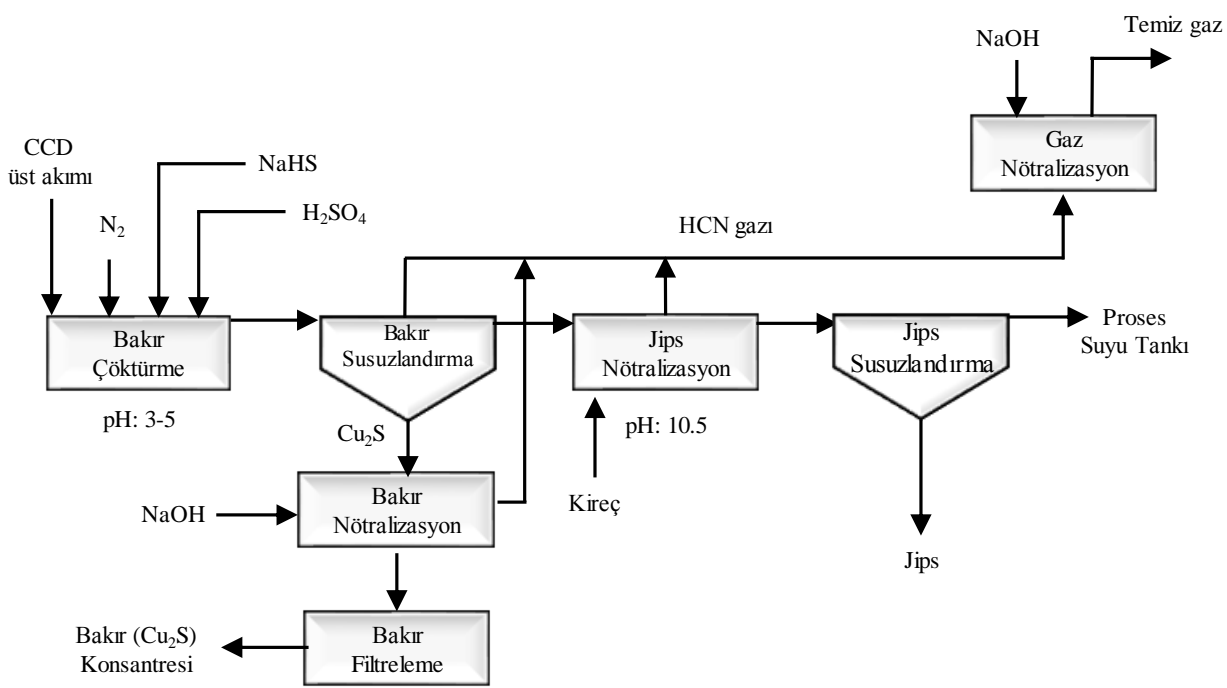

Şekil 9.Mastra altın madeninin SART prosesi akım şeması (Koza Altın İşletmeleri, 2011) 


\subsection{Proses Ekonomisi}

Siyanürün geri kazanılması, özellikle bakır içeriği yüksek cevherler için ekonomik bir zorunluluktur. Tablo 6'da sunulan bir ekonomik değerlendirmede, bakır içeriği yüksek altın cevherleri işleyen tesislerde siyanür bozundurma yerine geri kazanım proseslerinin (SART gibi) uygulanmas1nın ekonomik açıdan daha avantajlı olduğunu açıkça görülmektedir (SGS, 2013). Bakırın yan ürün olarak satılması işletme için ek bir gelir getirmektedir (Tablo 6). SART prosesinin sağladığ1 ekonomik avantajlara (Tablo 6) bağl1 olarak, SART tesisleri, ilk yatırım maliyetlerini birkaç y1l içinde finanse etmektedir. Örneğin, 750 $\mathrm{m}^{3} /$ saat kapasite ile çalışan ve $380 \mathrm{mg} / \mathrm{L} \mathrm{Cu}$ içeren çözelti işleyen bir SART tesisinin ilk yatırım maliyetini geri ödeme süresinin $1.5-2$ yıl olacağ tahmin edilmiştir (Fleming, 2003; Ford vd., 2008). İlk yatırım maliyetine yönelik yapılan bir analize göre, $\mathrm{Cu}_{2} \mathrm{~S}$ tikineri \%39, jips tikineri \%19 ve $\mathrm{Cu}_{2} \mathrm{~S}$ çöktürme reaktörü \%15 ile en önemli gider paylarını oluşturmaktadır (Stewart ve Kappes, 2012).

SART tesisinin yatırım maliyetini etkileyen önemli parametrelerden birisi de tesisin kurulacağı alanın maden sahasına uzaklığıdır. Eğer jips tikineri alt akışı susuzlandırmaya tabi tutulmaz ise yatırım ve işletme maliyetleri önemli ölçüde azaltılmış olmaktadır. SART jips atığı, yığın liçinde tabana serilerek (capping) ve CIP/CIL devresi öncesi besleme ile harmanlanarak kullanılabilmektedir (Baker vd., 2017).

Tablo 6. Bir $\mathrm{Au}-\mathrm{Cu}$ cevheri işleyen tesis için siyanür bozundurma ve geri kazanım maliyetlerinin karşılaştırılması (Siyanür tüketimi: $1 \mathrm{~kg} /$ ton NaCN; Çözünen bakır: $0.4 \mathrm{~kg} /$ ton) (2005 Fiyatlarına Göre) (SGS, 2013)

\begin{tabular}{lclc}
\hline Bozundurma & Maliyet (\$) & Geri Kazanım & Maliyet $\mathbf{( \$ )}$ \\
\hline Yeni Siyanür & 1.50 & İşletme & 0.60 \\
Bozundurma & 1.00 & İlk Yatııım & 0.30 \\
Toplam & 2.50 & Ara Toplam & 0.90 \\
& & Cu Kazancı & 0.40 \\
& & Net Kâr (\$/t) & 0.50 \\
\hline
\end{tabular}

SART prosesinin işletme maliyetini önemli seviyede etkileyen parametrelerden birisi de cevherdeki "siyanürde çözünen bakır (CN-çöz
Cu)" miktarıdır (Fleming, 2011). Şekil 11'de, yığı̆ liçi uygulaması için, cevherin $\mathrm{CN}-c ̧ c o ̈ z ~ C u$ içeriğine bağlı olarak işletme maliyetinin farklı durumlar için değişimi görülmektedir. Temel durum (6 \$/t) ((1) no'lu), cevherin CN-çöz $\mathrm{Cu}$ içeriğinden bağımsız olarak madencilik, kırma, liç, aktif karbon adsorpsiyonu, sıyırma, çevresel ve genel yönetim giderlerinden oluşmaktadır. Toplam maliyet, temel durum ve $\mathrm{CN}$-çöz $\mathrm{Cu}$ ile artan bir maliyet bileşenini kapsamaktadır. SART prosesi uygulanmadığı durumda ((2) no'lu) CNçöz $\mathrm{Cu}$ içeriği arttıkça işletme maliyeti de artarak 14 \$/t'a ulaşmaktadır. Dolayısıyla, CN-çöz $\mathrm{Cu}$ içeriği yüksek (>500 g/t) olan düşük tenörlü bir altın cevherinin SART uygulanmadan ekonomik olarak işletilmesi mümkün görünmemektedir. Diğer taraftan, SART prosesinin kullanılması durumunda ((3) no'lu), bakır $\left(\mathrm{Cu}_{2} \mathrm{~S}\right)$ yan ürün olarak satılmasa bile işletme maliyetleri önemli ölçüde azalmaktadır. Bakırın yan ürün olarak satıldığ1 durumda ((4) no'lu) ise işletme kâra geçmektedir (Fleming, 2011).

SART tesislerinin işletme maliyeti reaktif (asit, baz), nakliye, enerji vd. kalemlerden oluşmaktadır. Bir SART tesisine ait laboratuvar/pilot ölçekli testlere dayanılarak işletme giderlerinin dağılımı belirlemiştir (Şekil 10) (Ford vd., 2008). Buna göre, işletme giderlerinde en büyük payı $\% 28$ ile $\mathrm{NaSH}$ maliyeti oluşturmaktadır. $\mathrm{Baz}(\mathrm{NaOH}$ ve kireç) ve asit $\left(\mathrm{H}_{2} \mathrm{SO}_{4}\right)$ giderlerinin toplam pay1 da \%29'dur (Ford vd., 2008). Benzer şekilde, başka bir çalışmada, işletme giderleri arasında en yüksek payı (\%27) çöktürme aşamasında kullanılan NaSH almaktadır (Stewart ve Kappes, 2012). Yine aynı çalışmada, işletmenin asitleştirme ve nötralizasyon işlemleri \%40'lık bir paya sahiptir.

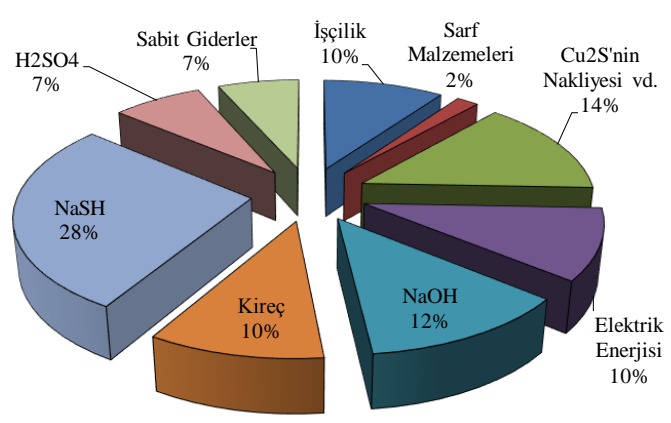

Şekil 10.SART tesisi işletme giderleri dağılımı (Ford vd., 2008) 


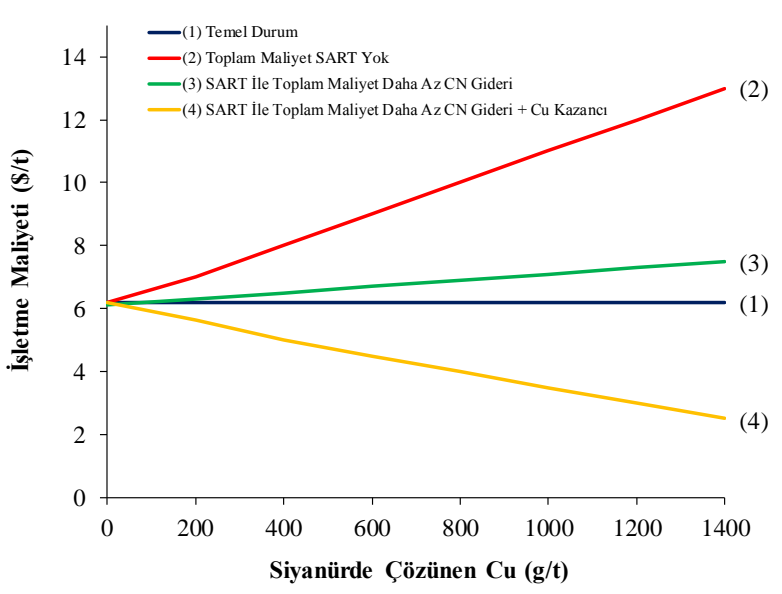

Şekil 11. Cevherin siyanürde çözünen bakır içeriğine $(\mathrm{g} / \mathrm{t})$ bağlı olarak bir yığın liçi tesisinin işletme maliyetinin değişimi (Fleming, 2011'den değiştirilerek)

\section{Sonuçlar}

Bakır içeriği yüksek cevherlerden $(>\% 0.5 \mathrm{Cu})$ ekonomik altın kazanımlarına ulaşabilmek için liç işleminin yüksek siyanür konsantrasyonlarında $(\mathrm{CN}: \mathrm{Cu}>4)$ gerçekleştirilmesi ve takiben liç çözeltisinden siyanürün geri kazanılması (ve bakırın yan ürün olarak eldesi) amacıyla SART prosesinin kullanılması endüstriyel olarak uygulanan seçeneklerden birisidir. SART prosesinin kimyası basit görünmesine karşın yüksek siyanür (ve bakır) geri kazanımı için sülfür dozaji, çöktürme süresi, bakır çökeleği $\left(\mathrm{Cu}_{2} \mathrm{~S}\right)$ tikinerde bekleme süresi vd. birçok parametrenin uygun şekilde seçilmesi gerekmektedir. Endüstriyel SART tesislerinde, uygun koşullarda yüksek siyanür geri kazanımlarına $(>\% 80)$ ulaşılmaktadır. Teknik ve ekonomik açıdan yüksek bir siyanür geri kazanım performansı elde etmek için, çöktürme işleminde $\mathrm{S}: \mathrm{Cu}$ oranının stokiyometrik oranda $(0.5)$ veya $\% 10-20$ fazlas 1 olması, çökme süresinin mümkün olduğunca kısa tutulması, oksijen ile çökeleğin temasın kesilmesi ve prosesin sürekli çalıştırılması önerilmektedir.

Aksi takdirde, bakır, $\mathrm{CuS}$ ve $\mathrm{CuCN}$ formlarında çökebilir veya bakır-siyanür kompleksleri halinde çözünerek bakır çökeleğinin saflığı düşer ve reaktif sarfiyatı artar. Henüz Dünya'daki SART tesisi sayıs1 10'un altındadır ve bir kısmı maden sahasına uzak ve kesikli çalışan küçük tesisler olduğu için prosesin maliyet, işletilebilirliği ve metalürjik performansı hakkında daha net bilgi elde edebilmek için daha fazla sayıda ve kesintisiz çalışan SART tesisinin kurulmasına ihtiyaç vardır. Cevherin siyanürde çözünen bakır içeriği arttıkça SART prosesinin ekonomik getirisi de yükselmektedir. SART prosesi ilk yatırım maliyetinin geri dönüşü yaklaşık 1.5-2 yıldır. SART prosesi, $\mathrm{Au}-\mathrm{Cu}$ cevherlerinden siyanür (ve yan ürün olarak bakır) geri kazanımı için önemli teknik ve ekonomik avantajlar sunmasına rağmen, endüstriyel uygulamalarda karşılaşılan bazı teknik sorunlar, proses hakkında daha ileri düzeyde bilgi/tecrübeye ihtiyaç duyulduğunu göstermektedir.

\section{Teşekkür}

Türkiye Bilimsel ve Teknolojik Araştırma Kurumu'na (TÜBİTAK) 213M492 no'lu proje kapsamında sağladığı desteklerden dolayı teşekkür ederiz. $\mathrm{Bu}$ makalenin ilk ve daha dar kapsamlı hali Uluslararası Madencilik ve Çevre Sempozyumu'nda (ISME 2017) sunulmuştur.

\section{Kaynaklar}

Adams, M. D., 2013. Impact of recycling cyanide and its reaction products on upstream unit operations, Minerals Engineering, 53, 241-255.

Adams, M., Lawrence, R., Bratty, M., 2008. Biogenic sulphide for cyanide recycle and copper recovery in gold-copper ore processing, Minerals Engineering, 21/6, 509-517.

Ahlatcı, F., 2016. Bakır ve pirit içeriği yüksek cevher ve konsantrelerden tiyosülfat liçi ile altın/gümüş kazanımı, Yüksek Lisans Tezi, Karadeniz Teknik Üniversitesi, Trabzon, s.89.

Alacer Gold, 2013. Çöpler gold mine-site visit presentation, (https://www.asx.com.au/asxpdf/20130912/pdf/ 42j9t1t291px52.pdf) (Erişim Tarihi: 02.01.2017).

Alacer Gold, 2014. Alacer Gold commissions chemical facility with SART plant, (https://www.prnewswire.com/newsreleases/alacer-gold-commissions-chemicalfacility-with-sart-plant-285832511.html), (Erişim Tarihi: 01.02.2017).

Baker, B., Rodriques, F., Littlejohn, P., 2017. SART implementation at gold mines in Latin America, The Conference of Metallurgists (COM), Ağustos 27-30, Paper No: 9489, Canadian Institute of Mining, Metallurgy and Petroleum, 8. 
Barry, T., 2013a. Silver Bull announces updated metallurgical test results on the silver mineralization at The Sierra Mojada Project, Coahuila, Mexico, Silver Bull Resources Inc., News Release, Temmuz, 1, (http://www.silverbullresources.com/s/news.asp ?ReportID=590659).

Barry, T., 2013b. Silver Bull completes positive preliminary economic assessment for The Sierra Mojada Project, Coahuila, Mexico, Silver Bull Resources Inc., News Release, Ekim, 1, (http://www.silverbullresources.com/s/news.asp ?ReportID=606026).

Barry, T., 2013c. Silver Bull CEO Tim Barry discusses Sierra Mojada PEA. In: Humphreys T (Hrsg.) (http://www.mining.com/web/silver-bull-ceotim-barry-discusses-sierra-mojada-pea/).

Barry, T., 2018. Silver Bull Intersects 10 Meters of Sulphide Mineralization Grading 347g/t Silver, $20.7 \%$ Zinc, $1.35 \%$ Lead \& $1.25 \%$ Copper, on the Sierra Mojada Project, Coahuila, Mexico (https://globenewswire.com/newsrelease/2018/03/14/1422158/0/en/Silver-BullIntersects-10-Meters-of-SulphideMineralization-Grading-347g-t-Silver-20-7Zinc-1-35-Lead-1-25-Copper-on-the-SierraMojada-Project-Coahuila-Mexico.html).

Barter, J., Lane, G., Mitchell, D., Kelson, R., Dunne, R., Trang, C., Dreisinger, D., 2001. Cyanide management by SART, Cyanide Soc. Ind. Econ. Asp., 549-562.

Bas, A. D., Koc, E., Yazici, E. Y., Deveci, H., 2015. Treatment of copper-rich gold ore by cyanide leaching, ammonia pretreatment and ammoniacal cyanide leaching, Transactions of Nonferrous Metals Society of China, 25, 597607.

Bas, A.D., Ozdemir, E., Yazici, E.Y., Celep, O., Deveci, H., 2011. Ammoniacal thiosulphate leaching of a copper-rich gold ore, The 15th Int. Conference on Environmental and Mineral Processing (EaMP), 83-90.

Bas, A.D., Yazici, E.Y., Deveci, H., 2012. Treatment of a copper- rich gold ore by ammonia assisted cyanide leaching, XXVI International Mineral Processing Congress (IMPC), New Delhi, Hindistan, 24-28 Eylül, 356-365.

Botz, M., Guzman, G., Sevilla, L., 2015. Campaign testing the Yanacocha SART plant with highcopper feed solution, SME Annual Meeting, Şubat 15-18, Society for Mining, Metallurgy \& Exploration, Denver, CO.

Botz, M., Kaczmarek, A., Orser, S., 2011. Managing copper in leach solution at the Çöpler gold mine: laboratory testing and process design,
Minerals \& Metallurgical Processing, 28, 133138.

BQE Water, 2017a. Mastra Mine, Koza Gold, (www.bqewater.com).

BQE Water, 2017b. Maricunga Mine, Kinross Gold, (www.bqewater.com).

Breuer, P.L., Jeffrey, M.I., Dai, X., 2005. Leaching and recovery of copper during the cyanidation of copper containing gold ores, in: treatment of gold ores - First Int. Symp., 44. Annual Conference of Metallurgists of CIM. Alberta, Canada, Editörler: Deschenes, G., Hodounin, D., Lorenzen, L., 279-293.

Bulatovic, S. M., 1997. Flotation behaviour of gold during processing of porphyry copper-gold ores and refractory gold-bearing sulphides, Minerals Engineering, 10, 895-908.

Corrans, I.J., Kyle, J.H., 2000. An overview of unit operations and processes used for treating gold and copper ores, Editör: Adams, M.D., Proc. of the Oretest Colloquium 99, 10 Kasim, Oretest Pty Ltd, Perth, Avustralya, 3-16.

Cuenca, H. E., Febre P. C., House, F. A., ARCADIS, 2012. The SART process: an attractive technology to recover copper and cyanide from gold mining, $2^{\circ}$ International Workshop, 12-13 Nisan 2012, Santiago-Şili.

Dai, X., Simons, A., Breuer, P., 2012. A review of copper cyanide recovery technologies for the cyanidation of copper containing gold ores, Minerals Engineering, 25, 1-13.

Deschênes, G. ve Prud'homme, P. J. H., 1997. Cyanidation of a copper-gold ore, International Journal of Mineral Processing, 50, 127-141.

Deschênes, G., Guo, H., Xia, C., Pratt, A., Fulton, M., Choi, Y., Price, J., 2012. A study of the effect of djurliete, bornite and chalcopyrite during the dissolution of gold with a solution of ammoniacyanide, Minerals, 2, 459-472.

Deveci, H., Yazıcı, E.Y., Alp, I., Uslu, T., 2006. Removal of cyanide from aqueous solutions by plain and metal-impregnated granular activated carbons, Int. J. Miner. Process, 79, 198-208.

Dreisinger, D., Vaughan, J., Lu, J., Wassink, B., WestSells, P., 2008. Treatment of the Carmack's copper-gold ore by acid leaching and cyanide Leaching with SART recovery of copper and cyanide from barren cyanide solution, In: C.A.

Estay, H., 2018. Designing the SART process - A review, Hydrometallurgy, 176, 147-165.

Estay, H., Carvajal, P., Arriagada, F., 2012. The SART Process: an attractive technology to recover 
copper and cyanide from gold mining, M2R2 Workshop, Expomin 2012, Nisan, Santiago, Şili,

(http://www.expomin.cl/marketing/pdf/2012/pre sentacion_arcadis.pdf) (Erişim Tarihi: 01.02.2017).

Estay, H., Carvajal, P., González, K., Vásquez, V., 2013. A theoratical study of SART precipitate generation: Operational and safety impacts, Editörler: F., Valenzuela, C., Young (Hrsg.), 5th In. Seminar on Process Hydrometallurgy (Hydroprocess), Temmuz, 10-12, Gecamin, Santiago, Şili, 153-160.

Fleming, C. A. ve Melashvili, M., 2016. A reexamination of the sacred cows in the SART process, 48th Annual Canadian Mineral Processors Conference, Ottawa, Ontario, 187205.

Fleming, C. A., 2016. Cyanide recovery, Gold Ore Processing, 2nd Edition, Chapter 36, Editör: Adams, M. D., Elsevier.

Fleming, C.A., 1992. Hydrometallurgy of precious metals recovery, Hydrometallurgy, 30, 127162.

Fleming, C.A., 2003. The economic and environmental case for recovering cyanide from gold plant tailings, SGS Minerals Services, Technical Paper \#2003-02.

Fleming, C.A., 2010. Cyanide management in the gold industry, SGS Minerals Services, Technical Paper \#2010-04.

Fleming, C.A., 2011. Dealing with cyanide-soluble copper in the gold mining industry, Fray International Symposium on Metals and Materials Processing in a Clean Environment, 27 Kasım-01 Aralık, Meksika, 173-190.

Ford, K., Fleming, C., Henderson, R., 2008. Application of the SART process to heap leaching of gold-copper ores at Maricunga, Chile. In: 40th Annual Meeting of the Canadian Mineral Processors, Ottawa, Ocak 22-24.

Forrest, K., Yan, D., Dunne, R., 2001. Optimisation of gold recovery by selective gold flotation for copper-gold-pyrite ores, Minerals Engineering, 14, 227-241.

Goh, S. W., Buckley, A. N., Lamb, R. N., 2006. Copper(II) sulfide?, Minerals Engineering,19, 204-208.

González, O. A., Alonso,F. N., Velasco C. J., Salas, A. U., 2013. Copper cyanide removal by precipitation with quaternary ammonium salts, Minerals Engineering, 42, 43-49.
Habashi, F., 1999. Amalgam and electrometallurgy, 4, 1st, Metallurgie Extractive Quebec.

Koc, E., Ahlatc1, F., Kuzu, M., Yazici, E.Y., Celep, O., Deveci, H., 2016. Recovery of silver from cyanide leach solutions of a pyritic gold concentrate by sodium sulphide precipitation, Proceedings of XV. International Mineral Processing Symposium and Exhibition (IMPS) (Editörler: Çelik, M.S., Bulut, G., Karakaş, F., Güven, O., Baştürkçü, H., Tarsus, Z.),19-21 Ekim, İstanbul, Türkiye, 823-834.

Kondos, P. D., Deschênes, G., Morrison, R. M., 1995. Process optimization studies in gold cyanidation, Hydrometallurgy, 39, 235-250.

Koza Altın İşletmeleri Tesis Bilgilendirme Sunumu, 15 Kasım 2011.

Kuyucak, N. ve Akcil, A., 2013. Cyanide and removal options from effluents in gold mining and metallurgical processes, Minerals Engineering, 50-51, 13-29.

La Brooy, S.R., Linge, H.G., Walker, G.S., 1994. Review of gold extraction from ores, Mineral Engineering, 7, 1213-1241.

Lawrence, R. W. ve Lopez, O., 2011. Improving the economics of gold-copper ore projects using SART technology.

Lopez, O., Petrovic, N., Krashenina, S., 2014. Copper and cyanide recovery from barren leach solution at the gold processing plant, XXVII. International Mineral Processing Congress (IMPC 2014), Santiago, Şili, 11.

MacPhail, P.K., Fleming, C., Sarbutt, K., 1998. Cyanide recovery by the SART Process for the Lobo-Marte Project, Şili, Randol Gold and Silver Forum, Denver.

Marsden, J. ve House, I., 2006. The chemistry of gold extraction, Society for Mining, Metallurgy, and Exploration, USA.

Medusa, 2009. Software for Chemical Equilibrium Diagrams, 32 bit version, Royal Institute of Technology, İsveç.

Mokone, T. P., van Hille, R. P., Lewis, A. E., 2010. Effect of solution chemistry on particle characteristics during metal sulfide precipitation, Journal of Colloid and Interface Science, 351, 10-18.

Mudder, T. I. ve Botz, M. M., 2001b. The cyanide monogragh, Mining Journal Books Ltd., London, 605.

Mudder, T. I. ve Botz, M.M., 2001a. The chemistry and treatment of cyanidation wastes, Mining Journal Books Ltd, London, 393. 
Muir, D. M. ve Aylmore, M. G., 2005. Thiosulfate as an alternative lixiviant to cyanide for gold ores. Editörler: Adams, M. D. ve Wills, B. A., Developments in Mineral Processing, Elsevier, 541-560.

Muir, D. M., La Brooy, S. R., Fenton, K., 1991. Processing copper-gold ores with ammonia or ammonia-cyanide solutions, World Gold 1991, 21-25 Nisan, Cairns Qld., 145-150.

Muir, D.M., 2011. A review of the selective leaching of gold from oxidised copper-gold ores with ammonia-cyanide and new insights for plant control and operation, Minerals Engineering, 24, 576-582.

Nodwell, M., Kratochvil, D., Lopez, O., 2012. Risk management and mitigation for the SART copper cyanide recovery process, HYDROPROCESS 2012, 4th International Seminar on Process Hydrometallurgy, 12-13 Temmuz, Santiago, Şili, 1-7.

Parga, J. R., 2011. Copper and cyanide recovery in cyanidation effluents, Advances in Chemical Engineering and Science, 01, 191-197.

Potter, G.M., Tucson, A., Bergmann, A., Haidlen, U., 1986. Process of recovering copper and of optionally recovering gold by leaching of oxide and sulfide-containing materials with watersoluble cyanides, US Patent 4587110, 6 Mayıs.

Ritcey, G. M., 2005. Tailings management in gold plants, Hydrometallurgy, 78, 3-20.

Sceresini, B. ve Breuer, P., 2016. Gold-copper ores, Gold Ore Processing, 2nd Edition, Chapter 43, Editör: Adams, M. D., Elsevier.

Sceresini, B., 2005. Gold-copper ores, Advances in Gold Ore Processing, Western Australia, Chapter 32, Editörler: Adams, M. D. ve Wills, B. A., Elsevier.

SGS, 2008. Application of the SART process to heap leaching of gold-copper ores at Maricunga, Chile, SGS Minerals Services Technical Paper 2008-51.

SGS, 2009. Cyanide Recovery, Technical Paper, No. T3 SGS 019, SGS Minerals Services.

SGS, 2013. Cyanide recovery, SGS Minerals Services - T3 SGS 019, 11-2013.

Simons, A. ve Breuer, P., 2013a. Fundamental investigations of SART for cyanide and copper
Recovery, CIM J, 4 (3), 145-152 Canadian Institute of Mining, Metallurgy and Petroleum.

Simons, A. ve Breuer, P., 2013b. The impact of residence time on copper recovery in Telfer Gold Mine's cyanide recycling process. In: World Gold 2013, Brisbane, Queensland, Avustralya. Australasian Institute of Mining and Metallurgy, Melbourne, 189-196, 26-29 Eylül.

Stewart, M. ve Kappes, D., 2012. SART for copper control in cyanide heap leaching, SAIMM, 112, 1037-1043.

Torre, M., Bachiller, D., Rendueles, M., Menéndez, C. O., Díaz, M., 2006. Cyanide recovery from gold extraction process waste effluents by ion exchange I. equilibrium and kinetics, Solvent Extraction and Ion Exchange, 24, 99-117.

Van Deventer, J., Bazhko, V., Yahorava, V., 2014. Comparison of gold-selective ion exchange resins and activated carbon for the recovery of gold from copper-gold leach liquors, GoldPrecious Metals Conference (ALTA 2014), Perth, Avustralya, 17.

Xie, F., Dreisinger, D., Doyle, F., 2013. A review on recovery of copper and cyanide from waste cyanide solutions, 34:6, 387-411.

Yazıc1, E. Y., 2005. Atık sulardaki siyanürün hidrojen peroksit, aktif karbon adsorpsiyonu ve ses ötesi dalgalarla uzaklaştırılması, Yüksek Lisans Tezi, 141 syf., Karadeniz Teknik Üniversitesi, Trabzon.

Yazici, E. Y., Ahlatci, F., Koc, E., Celep, O., Deveci, H., 2015. Pre-treatment of a copper-rich gold ore for elimination of copper interference, 8th European Metallurgical Conference (EMC), Düsseldorf, 601-613.

Yılmaz, E., Yazıc1, E. Y., Celep, O., Deveci, H., 2019. Liç atıklarından siyanürün geri kazanımı yöntemleri, Bilimsel Madencilik Dergisi, 58(1), 53-71.

Young, PRT, Anderson, C.G., Choi, Y. (Hrsg.), Hydrometallurgy 2008: Proceedings of the 6th International Symposium, Society of Mining, Metallurgy and Exploration Inc. (SME), 740749.

Zhang, Y., Fang, Z., Muhammed, M., 1997. On the solution chemistry of cyanidation of gold and silver bearing sulphide ores, A critical evaluation of thermodynamic calculations, Hydrometallurgy, 46, 251-269. 